\title{
Evidence for Voltage-activated Outward Currents in the Neuropilar Membrane of Locust Nonspiking Local Interneurons
}

\author{
Gilles Laurent ${ }^{\mathrm{a}}$ \\ Department of Zoology, University of Cambridge, CB2 3EJ Cambridge, England and California Institute of Technology, \\ Computation and Neural Systems Program, Biology Division, 139-74, Pasadena, CA 91125
}

Outward currents activated by depolarization were studied in the neuropilar membrane of locust nonspiking local interneurons, using the single-electrode voltage-clamp technique in situ. Preliminary observation of these currents in 272 neurons revealed two families. The first and most commonly observed ( $85 \%$ of recordings) showed a large transient current followed by a slowly decaying/late current. The second (15\% of recordings) showed an additional outward current with a slow rate of activation, a peak within 100-150 msec, and a slow rate of inactivation. Only neurons of the first type were studied further. The transient current was activated by depolarization around $-60 \mathrm{mV}$, with a time to peak of $\approx 11 \mathrm{msec}$ at $-50 \mathrm{mV}$ and less than $3 \mathrm{msec}$ at -20 $\mathrm{mV}$. This current decayed exponentially, with a time constant of $8.1 \pm 1.6 \mathrm{msec}$ ( $n=8$ interneurons) at $-30 \mathrm{mV}$. This time constant of inactivation did not appear to depend strongly on membrane voltage, in the range in which it was studied. A second and longer time constant of inactivation of 50-400 msec could not be assigned to either of the transient and late components of the outward current. The ratio of transient-to-late current varied between 1.6 and 5.4 , with a mean of about 2.5. The reversal potential for the transient current could, on average, be shifted by $14 \mathrm{mV}$ by a threefold increase in the bath $K^{+}$concentration, indicating that $K^{+}$is a charge carrier for the current. The transient current became inactivated with maintained depolarization and appeared halfinactivated at about $-60 \mathrm{mV}$ (slope factor $k_{1 / 2}=8 \mathrm{mV}$ ). This current was thus not fully inactivated at "resting" potential (average, $-58 \mathrm{mV}$ ). Recovery from inactivation followed a single exponential time course, with a time constant of $\approx 100$ $\mathrm{msec}$ at $-80 \mathrm{mV}$. The time course of recovery from inactivation of the transient current was well correlated with that of the recovery of transient outward rectification, as measured in current-clamp recording. Tetraethylammonium, at a bath concentration of $10 \mathrm{~mm}$ reduced the transient current by $70 \%$ and the delayed current by $60 \%$. 4-Aminopyridine, at a bath concentration of $5 \mathrm{~mm}$, had a significant effect in

\footnotetext{
Received Sept. 13, 1990; revised Jan. 8, 1991; accepted Jan. 11, 1991.

This work was supported by the Royal Society, the Science and Engineering Research Council (SERC; UK), the Hasselblad Foundation, the Human Frontier Science Program, the Searle Scholars Program, and the California Institute of Technology (Biomedical Research Support Grant Program, NIH). I am grateful to Malcolm Burrows, Roger Hardie, Sylvie Ryckebush, and Mark Tanouye for their comments on the manuscript, to Drs. Michael Bastiani, Brian Mulloney, Robert Josephson, and Michael E. Adams for providing me with the insects to start the Caltech locust colony, and to Renee Thorf for typing the manuscript.

a Present address: California Institute of Technology, Computation and Neural Systems Program, Biology Division, 139-74, Pasadena, CA 91125.

Copyright (C) 1991 Society for Neuroscience $0270-6474 / 91 / 111713-14 \$ 03.00 / 0$
}

only two of five interneurons, reducing the transient current by $\approx 85 \%$ and the late current by $\approx 15 \%$. Quinidine at a bath concentration of $100 \mu \mathrm{M}$ was ineffective. Although these blockers did not allow a clear pharmacological separation of the currents, they were effective in reducing the outward rectification observed in current clamp during step depolarization. Their presence never unmasked regenerative events such as action potentials in the nonspiking local interneurons. Cobalt chloride ( $25 \mathrm{~mm}$ ) had no effect on either current. These results suggest that the outward currents activated by depolarization are similar to the "A-" and "delayed-rectifer" currents, originally described in other invertebrate neurons.

Recent work carried out principally on Drosophila neurons and muscle has led to a wealth of data on the genetics and biophysics of voltagc-activated channels (Kamb et al., 1987; Papazian et al., 1987; Solc et al., 1987; Iverson et al., 1988; Timpe et al., 1988; O'Dowd et al., 1989; Singh and Wu, 1989; Solc and Aldrich, 1990; Wei et al., 1990; Zagotta and Aldrich, 1990). It is now suspected, for example, that most of the voltage-activated potassium channels in Drosophila, whether fast/transient or slow/ noninactivating, originate from an extended gene family (Shaker, Shal, Shab, and Shaw; Wei et al., 1990) in addition to resulting from alternative splicing of single genes within this family (e.g., Shaker gene: Kamb et al., 1988; Pongs et al., 1988; Schwartz et al., 1988). In these studies, however, Drosophila neurons were unidentified and, as a consequence, were treated as homogeneous and interchangeable. The brain of a fly (Musca), however, contains some $3.38 \times 10^{5}$ neurons $\left(\approx 2.57 \times 10^{5}\right.$ outside of the optic lobes; Strausfeld, 1976), distributed in many discrete populations. If, as is likely, Drosophila neurons show the same physiological and anatomical variability as those that have been identified and described in the nervous system of other insects (e.g., fly: Hausen, 1982; locust: Siegler and Burrows, 1979; Robertson and Pearson, 1985; Watkins et al., 1985; Laurent, 1987; cricket: Schildberger, 1984; tobacco horn moth: Christensen and Hildebrand, 1987), we might expect that the various membrane currents found in the neurons of these populations be somewhat "suited" to the integrative role that they play in well-defined circuits (see, e.g., Hardie, 1989; Hardie and Weckström, 1990; Hardie et al., 1991 for the role of outward conductances in lamina monopolar interneurons in the fly retina). The study undertaken here is thus designed in part to try to study the membrane properties of well-characterized insect neurons and to relate these membrane properties to their integrative function in already well-defined sensory-motor circuits. 
Local interneurons in the thoracic ganglia of the locust are of two main types. The first uses action potentials as the mode of intercellular communication ("spiking local interneurons"; Burrows and Siegler, 1982), and the second uses graded signals only ("nonspiking local interneurons"; Pearson and Fourtner, 1975; Burrows and Sicgler, 1976). These two types of interneurons are found in the same circuits, and both process signals of mechanosensory origin (Burrows and Laurent, 1989). The originally plausible hypothesis that nonspiking integration should occur in local circuits because "short-range" intra- and intercellular communication does not require action potentials was thus proved insufficient by the discovery of local interneurons that use action potentials. Serial reconstruction of the neurites of both types of local interneurons using the electron microscope revealed another fundamental difference between them. Whereas spiking local interneurons have essentially segregated fields of input and output synapses (Watson and Burrows, 1985), nonspiking interneurons, on the contrary, show intermingled input and output synapses on their neurites and thus a lack of functional polarization (Watson and Burrows, 1988). These and other recent physiological results on the integrative properties of nonspiking interneurons suggest that single nonspiking interneurons might carry out local dendritic computations and thereby become more than single integrative units (Laurent and Burrows, $1989 \mathrm{~b}$ ).

In a previous paper, I described the voltage-dependent nonlinearities of the membrane of nonspiking interneurons, revealed using the discontinuous current-clamp technique and neuropilar intracellular recording (Laurent, 1990). One main result of this investigation was that the neuropilar membrane of nonspiking interneurons shows a conspicuous outward rectification upon depolarization. Consequently, the temporal features of synaptic potentials and their integration by the nonspiking membrane appeared to depend greatly not only on the membrane polarization, but also on the dynamic characteristics of the membrane polarization (Laurent, 1990). In the present study, I used the single-electrode voltage-clamp technique to try to characterize the neuropilar outward currents activated by depolarization, which are presumably responsible for the voltage-dependent integrative properties of nonspiking local interneurons.

\section{Materials and Methods}

Experiments were performed on adult locusts, Schistocerca gregaria (Forskal; in Cambridge, UK) and Schistocerca americana (in Pasadena, $\mathrm{CA}$ ), of either sex, from crowded lab colonies. The results presented here were gathered from 272 intracellular recordings of nonspiking interneurons in 123 animals. All the experiments presented were performed 4-36 times. No significant difference was found between the two species. The average resting potential of the interneurons in the isolated preparation was, for example, $-58 \pm 6 \mathrm{mV}(n=85)$ in $S$. gregaria and $-56.5 \pm 6.6 \mathrm{mV}(n=45)$ in $S$. americana.

Preparation. All experiments were performed in an isolated preparation described in detail in a previous paper (Laurent, 1990). Briefly, the meso- and metathoracic ganglia were removed from the thorax of the animal, with the surrounding tracheal supply and air sacs undisturbed, and were pinned down in a 10-mm-diameter chamber lined with Sylgard 184 (Dow Corning Co., Midland, MI). The preparation was superfused with oxygenated locust saline $(\mathrm{NaCl}, 140 \mathrm{~mm} ; \mathrm{KCl}, 10$ $\mathrm{mm} ; \mathrm{CaCl}_{2}, 4 \mathrm{mM} ; \mathrm{NaHCO}_{3}, 4 \mathrm{~mm} ; \mathrm{NaCl}_{2} \mathrm{PO}_{4}, 6 \mathrm{~mm}$ ) supplemented with $3.4 \%(\mathrm{w} / \mathrm{v})$ sucrose. The tracheae were teased open at the surface of the saline. The temperature of the preparation was constantly monitored and varied, in different experiments, between $20^{\circ} \mathrm{C}$ and $29^{\circ} \mathrm{C}$. The dorsal surface of the metathoracic ganglion was treated with $1 \%$ $(w / v)$ protease (Sigma, type XIV) for $30 \mathrm{sec}$, after which the saline was thoroughly washed. Desheathing of the metathoracic ganglion was only done in those experiments that required penetration of superfused pharmacological agents and changes in extracellular ionic concentrations. Desheathing was not done routinely because it was detrimental to recording stability.

Recording. Intracellular recordings were made exclusively from the neuropilar processes of nonspiking local interneurons, identified on established criteria (Burrows and Siegler, 1978; Laurent, 1990). Thickwalled microelectrodes (Clark Medical Instruments, Reading, UK) were coated with Sylgard down to $\approx 100-200 \mu \mathrm{m}$ from their tip, to decrease the capacitive coupling to the bath, and then filled with $3 \mathrm{M} \mathrm{K}$-acetate. The DC resistance of the electrodes was typically between 50 and 90 $\mathrm{M} \Omega$. Switched current- and voltage-clamp recordings were made using an Axoclamp-2A (Axon Instruments Inc.) amplifier. After optimal capacity compensation and reduction of electrode and stray capacitance (see Wilson and Goldner, 1975; Merickel, 1980; Finkell and Redman, 1984), switching rates of $4-6.5 \mathrm{kHz}$ were routinely obtained, allowing nearly complete electrode voltage decay before sampling (duty cycle, $30 \%$ ). The headstage voltage was always monitored on a separate oscilloscope, to ensure complete settling during each switching cycle. Under these conditions $\pm 3 \mathrm{nA}$ of current could be injected directly into the bath in current-clamp mode with no morc than $\pm 2-\mathrm{mV}$ voltage drop across the microelectrode. Only electrodes that passed this test were kept for intracellular recording. Clamp gain was between 1.5 and $8 \mathrm{nA} / \mathrm{mV}$, and data were usually filtered at 1 or $3 \mathrm{kHz}$. Data were recorded on a store-7-DS Racal FM tape recorder (frequency response flat to $5 \mathrm{kHz}$ ) or an 8-channel digital audiotape recorder (Sony/Biologic) and analyzed off line on an AT-compatible microcomputer, after digitization at $5-15 \mathrm{kHz}$ with a CED-1401 (Cambridge Electronic Design Ltd., Cambridge, UK) AD/DA interface. Stimulating pulse regimes and ramps for voltage-clamp experiments were generated by a stimulator or by the computer. Leak current subtraction was done digitally, using averaged templates obtained with each interneuron from corresponding hyperpolarizing voltage steps. No inward rectification (Katz, 1949) was ever seen in these interneurons (Laurent, 1990). Single- and doubleexponential curve fittings werc accomplished with the microcomputer, using a sum of the squares error calculation. Most chemicals, including 4-aminopyridine (4-AP), tetraethylammonium (TEA), and quinidine sulfate were obtained from Sigma Chemical $\mathrm{Co}$. $\mathrm{CoCl}_{2}$ was obtained from Mallinckrodt Inc.

Space clamp in discontinuous-clamp recording configuration. Charging transients evoked in the neuropilar membrane of the nonspiking local interneurons by low current injection could only be fit with the sum of at least two exponentials (Laurent, 1990). The existence of one (at least) equalizing time constant is often interpreted as an indication of charge redistribution on nonisopotential regions of the membrane (Rall, 1969, 1989). The nonspiking interneurons were thus unlikely to be isopotential, and satisfactory space clamp might be inadequate. The value of the electrotonic length of the sealed cylinder most equivalent to the neurons (Rall, 1969, 1977) calculated from the experimental values of the membrane and equalizing time constants was relatively low, however, at 1-1.5 (Laurent, 1990). To evaluate the quality of the space clamp, the time course of the capacitive currents during small voltage steps was observed. During single-electrode voltage clamp, the settling of the capacitive current $\left(I_{c}\right)$ at the onset of small voltage steps (in regions of potentials too negative to activate voltage-gated conductances) was not simultaneous to the settling of the membrane voltage (Fig. 1 $A$, dotted line). The time course of this current was always fit by one or two exponentials with a longer time constant of 2-20 msec. Only recordings with a single, short ( $<3 \mathrm{msec}$ for \pm 10 -mV steps) exponential decay of $I_{c}$ were kept for quantitative analysis. Only 36 out of 253 interneurons met this criterion. The currents observed in the remainder of the interneurons were, however, qualitatively similar to those characterized in the neurons kept for analysis. An example is shown in Figure $1 B$, where $I_{c}$ decays with a time constant of $2.7 \mathrm{msec}$. Positive and negative voltage steps usually generated symmetrical currents, as shown in Figure $1 A$, so that the sum and signal average of corresponding positive and negative current traces was generally flat after $1-2 \mathrm{msec}$ (Fig. 1 $A$, trace $\Sigma$ ). All quantification of voltage-activated currents evoked at a given voltage was carried out after addition of the currents evoked by the corresponding symmetrical voltage step. This led to current traces devoid of large capacitative-current artifacts (e.g., Fig. $3 A$ ) and to leak subtraction. Quantitative results are to be considered only as indicative, however, because of the inherent limitations of point clamping with this single-electrode discontinuous-clamp method (Johnston and Brown, 1983). During large voltage steps evoking large currents, voltage control was slow as a result of the properties of the single-electrode clamp, and 


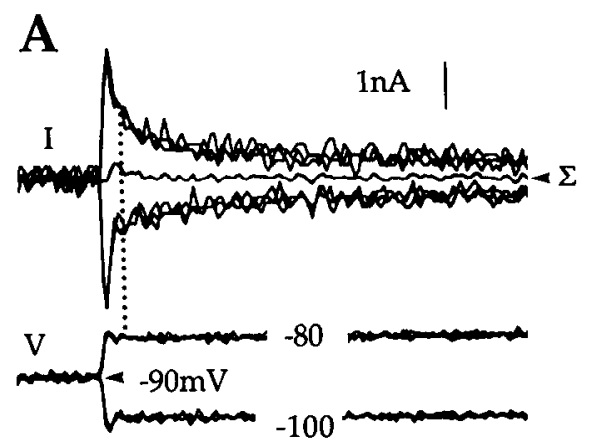

$15 \mathrm{msec}$
B

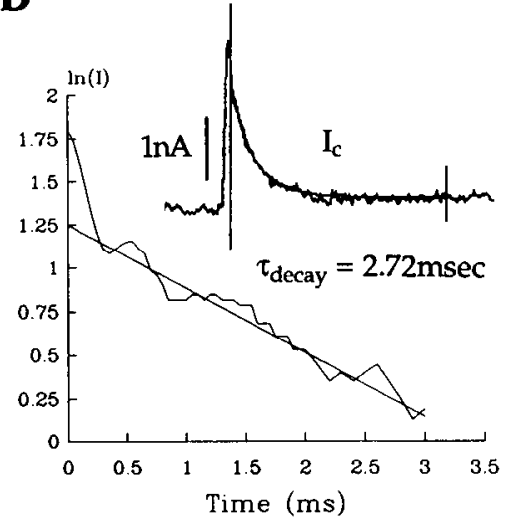

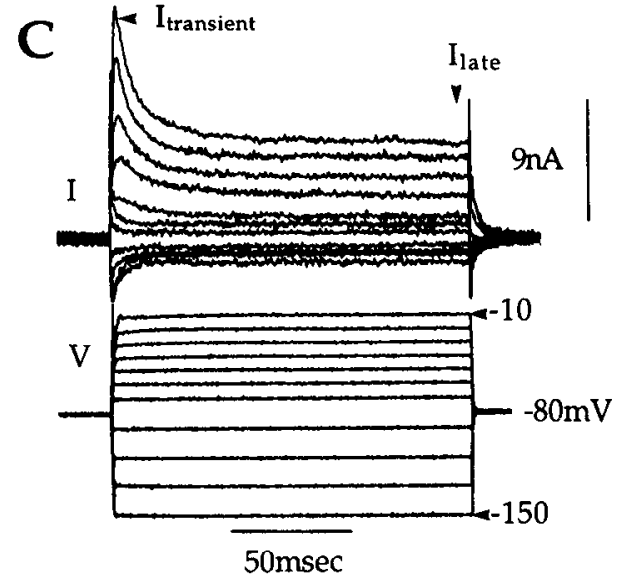

Figure 1. Decay of capacitive currents and control of membrane voltage during single electrode voltage clamp. $A$, The membrane of this interneuron, clamped at $-90 \mathrm{mV}$, is stepped to -80 and $-100 \mathrm{mV}$. The capacitive current generated by the imposed change in voltage outlasts the stabilization of membrane voltage (vertical dotted line). The steady-state current, representing the leak conductance, is reached within 6 msec. The signal average of the six traces $(\Sigma)$ is flat after $2 \mathrm{msec}$. $I$, current; $V$, voltage. Temperature, $23^{\circ} \mathrm{C}$; sampling rate (SR), $5.2 \mathrm{kHz}$; resting potential (RP) $-57 \mathrm{mV}$. B. Semilogarithmic plot of the capacitive current decay for a different interneuron during a $10-\mathrm{mV}$ voltage step from $-83 \mathrm{mV}$. The time constant of decay deduced from the plot is used to fit the original averaged data (inset). Temperature, $21^{\circ} \mathrm{C} ; \mathrm{RP},-63 \mathrm{mV} ; \mathrm{SR}, 6.8 \mathrm{kHz}$ (average of 16 traces). C, Voltage-clamp steps from a holding potential of $-80 \mathrm{mV}$, showing that reasonably good control of membrane voltage is accomplished from about $3 \mathrm{msec}$ after the onset of the voltage steps. Note the two outward currents (transient and late). Each trace is an average of four. Temperature, $23^{\circ} \mathrm{C} ; \mathrm{SR}, 6.6 \mathrm{kHz} ; \mathrm{RP},-65 \mathrm{mV}$.

the instantaneous membrane potential used for quantification was always the true recorded potential rather than the command voltage. An example of voltage-clamp steps is shown in Figure $1 C$, where the membrane was taken from a holding potential of $-80 \mathrm{mV}$ up to $-10 \mathrm{mV}$ in successive $10-\mathrm{mV}$ steps. Good apparent control of the membrane voltage was accomplished from $\approx 3 \mathrm{msec}$ after the onset of the voltage step. Exponential relaxation fits were therefore only performed with current traces once the membrane voltage had been stabilized, that is, gencrally at least $3-5 \mathrm{msec}$ after the onset of the voltage steps.

\section{Results}

\section{Two types of responses}

Figure 2 illustrates the two broad categories of responses observed in nonspiking interneurons during depolarizing steps imposed under voltage clamp and in normal saline. The interneuron in Figure $2 A$ was stepped to a constant command voltagc of $-33 \mathrm{mV}$ from conditioning voltages of -93 to $-38 \mathrm{mV}$. Depolarizing pulses evoked the activation of a large early and rapidly inactivating (transient) outward current $\left(I_{\text {transient }}\right.$; Fig. $2 A$ ) and that of a smaller and sustained or slowly decaying outward current $\left(I_{\text {late }}\right)$. This pattern of response was observed in $85 \%$ of recordings. The second and least frequent type of response is shown in Figure $2 B$. Under the same regime of stimulation from conditioning voltages of -75 to $-35 \mathrm{mV}$ to a constant command voltage of $-30 \mathrm{mV}$, this interneuron expressed, in addition to the transient and late currents seen in all neurons, a third outward current. This current activated slowly, reaching a peak $100-150 \mathrm{msec}$ after the onset of the voltage step, and decayed slowly to reach steady state within 300-500 msec (Fig. $2 B, I_{2}$ ). Interneurons with this response profile in voltage clamp were also studied in current clamp. An example is shown in Figure $2 C$. During small $(+1-n \mathrm{~A})$ depolarizing current pulses from a resting potential of $-55 \mathrm{mV}$, the membrane depolarized in two phases, due to successive transient and late outward rectifications (Fig. $2 \mathrm{Ci}$ ), as described previously for other nonspiking local interneurons (Laurent, 1990). With larger currents, the two successive depolarizing phases were followed by membrane-potential oscillations of 5-8 $\mathrm{mV}$ peak-to-peak amplitude
(Fig. 2Cii). These oscillations could be observed reliably, but only within a narrow range of voltages $(<10-15 \mathrm{mV})$. With still larger currents and only in some recordings, slow regenerative potentials of about $20-\mathrm{mV}$ amplitude could sometimes be evoked, whose frequency increased with increasing currents, but to no more than $\approx 8 \mathrm{~Hz}$ (Fig. 2 Ciii). Such regenerative potentials were observed in only 5 of the 272 recordings. The remainder of this paper will deal exclusively with the characterization of the outward currents in the first and most commonly recorded type.

\section{Outward potassium currents}

Voltage steps of 150-msec duration were delivered from holding potentials of -90 to $-70 \mathrm{mV}$ every $1.5 \mathrm{sec}$. After signal averaging of 4-16 traces and leak current subtraction, the net outward currents could be characterized and their activation studied (Fig. 3A). The total current was activated around -60 $\mathrm{mV}$, and the transient current, measured at its peak, increased steeply to about $23 \mathrm{nA}$ at $-30 \mathrm{mV}$. Given a corresponding reversal potential of about $-75 \mathrm{mV}$ (see below), this conductance was about $500 \mathrm{nS}$ at $-30 \mathrm{mV}$. Such large conductance generally precluded an accurate control of the membrane potential with the single-electrode clamp circuit at voltages more positive than $-20 \mathrm{mV}$. Near-maximum conductance was thus only rarely obtained. The ratio of transient to late current in the 36 recordings studied in detail varied greatly, between $\approx 1.6$ ( $n=12$ interneurons) and $5.5(n=1$; Fig. $3 C$ ). Half of the recordings, however, yielded ratios of $1.5-2.5$ (Fig. $3 C$ ). The steady-state inactivation characteristics of the transient and late currents (Fig. 2A) appeared similar to those of the transient A-current $\left(I_{\mathrm{A}}\right.$; Hagiwara et al., 1961; Connor and Stevens, 1971; Neher, 1971) and of the delayed-rectifier current $\left(I_{\mathrm{kV}}\right.$; Hodgkin and Huxley, 1952). Experiments were thus carried out to investigate the ionic basis of the transient conductance.

Nonspiking local interneurons were held at voltages between -75 and $-90 \mathrm{mV}$ and depolarized by $50 \mathrm{mV}$ in $4-\mathrm{msec}-$ long 
A

Figure 2. Outward currents in voltage-clamped nonspiking interneurons. $A$, This interneuron is stepped to -33 $\mathrm{mV}$ after 1 -sec-long conditioning prepulses at -93 to $-38 \mathrm{mV}$. Two outward currents can be distinguished: a transient and rapidly inactivating current $\left(I_{\text {transiem }}\right)$ and a late or slowly inactivating one $\left(I_{\text {tate }}\right)$. Temperature, $27^{\circ} \mathrm{C}$; $\mathrm{SR}, 5.8 \mathrm{kHz} ; \mathrm{RP}\left(V_{r}\right),-53 \mathrm{mV} . B, \mathrm{~A}$ second interneuron is stepped to -30 $\mathrm{mV}$ after 1-sec-long conditioning prepulses at -75 to $-35 \mathrm{mV}$. In addition to the transient and late currents, a third, slowly activating and slowly inactivating current can be seen $\left(I_{2}\right)$. Note that the time scales are different in $A$ and $B$. Temperature, $23.7^{\circ} \mathrm{C} ; \mathrm{SR}, 5.7 \mathrm{kHz} ; \mathrm{RP}$, $-55 \mathrm{mV}$. C., Current-clamp recordings of an interneuron showing outward currents such as in interneuron in $B . i,+1$ $\mathrm{n} \wedge$ pulses; $i i,+2 \mathrm{n} \wedge$ pulses (note the membrane-potential oscillations during the late part of the depolarizing pulses); $i i i,+3$ and $+4 \mathrm{nA}$. Note the slow regenerative potentials. Temperature, $24^{\circ} \mathrm{C} ; \mathrm{SR}, 5.2 \mathrm{kHz} ; \mathrm{RP},-57 \mathrm{mV}$.

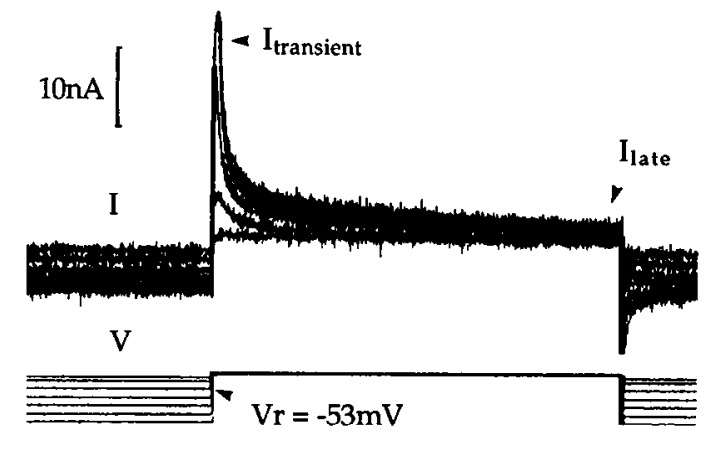

$100 \mathrm{msec}$

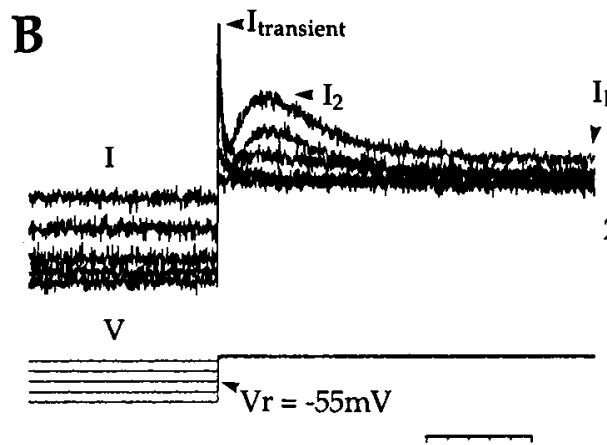

$250 \mathrm{msec}$
Ci

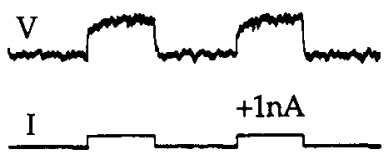

Cii

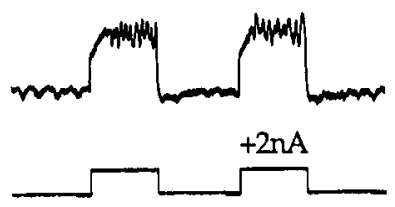

$20 \mathrm{mV}$

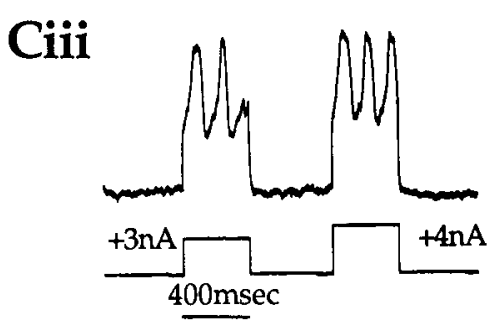

pulses. The membrane was then repolarized to potentials from -35 to $-120 \mathrm{mV}$, and the tail current recorded at each potential was measured as the difference between the peak current and that at the end of the pulse ( $45 \mathrm{msec}$ later). In $10 \mathrm{~mm}$ extracellular $\mathrm{K}^{+}$, the instantaneous tail current was outward at potentials from $-10 \mathrm{mV}$ to about $-80 \mathrm{mV}$, where it reversed (Fig. $4 A$ ). In 30 $\mathrm{mM} \mathrm{K} \mathrm{K}^{+}$(bath concentration), the tail current reversed between -55 and $-60 \mathrm{mV}$ (Fig. $4 B$ ). Shifts in reversal potential could not be established with individual interneurons, because the time needed for the extracellular ionic concentrations to change in the neuropil was greater than the time for which a good penetration could be maintained. Experiments at each bath $\mathrm{K}^{+}$ concentration were thus performed with different interneurons, but in the same animals. Furthermore, though the bath $\mathrm{K}^{+}$ concentration was known, the concentration reached in the neuropil after $1-2 \mathrm{hr}$ of the 10 - or $30-\mathrm{mm} \mathrm{K}^{+}$saline perfusion was unknown, and possibly much less (Schofield, 1990). The instantaneous current-voltage relations corresponding to the interneurons in Figure $4, A$ and $B$, are shown in Figure $4 C$, indicating a difference of about $20 \mathrm{mV}$ in reversal potential, with a threefold increase in $\mathrm{K}^{+}$concentration. The average value of the shift in reversal potential was $14 \mathrm{mV}$, with average values of reversal potentials of $-75 \pm 7 \mathrm{mV}$ ( $n=13$ interneurons) in $10 \mathrm{~mm}$ extracellular $\mathrm{K}^{+}$and $-61 \pm 8 \mathrm{mV}$ ( $n=6$ interneurons) in $30 \mathrm{mM} \mathrm{K}^{+}$. Although this shift is only $55 \%$ of that expected from the Nernst equation $(27 \mathrm{mV})$, it indicates nevertheless that $\mathrm{K}^{+}$is a charge carrier for this current. The decay of the tail current at $-35 \mathrm{mV}$ in $10 \mathrm{~mm}$ extracellular $\mathrm{K}^{+}$followed a single exponential, with a time constant of about 7-8 $\mathrm{msec}$ (Fig. $4 D$ ).

\section{Separation of the transient and late currents}

Preliminary experiments using the known pharmacological blockers of $\mathrm{K}^{+}$currents 4-AP, TEA, and quinidine did not appcar sclcctivc cnough (see below) and were thus abandoned as a means to separate the two current families. Rather, differences in their respective steady-state inactivation characteristics were used. Currents evoked by depolarizing steps to a given potential from a conditioning voltage of -50 or $-40 \mathrm{mV}$ were subtracted from those evoked by steps to the same potential from -90 $\mathrm{mV}$. An example is shown in Figure 5, where the nonspiking interneuron was depolarized in $10-\mathrm{mV}$ steps up to $-10 \mathrm{mV}$ from successive holding voltages of $-90 \mathrm{mV}$ and $-50 \mathrm{mV}$. The currents evoked from $-90 \mathrm{mV}$ contained both the transient and the late components (Fig. $5 \mathrm{~A}$ ), whereas those evoked from -50 $\mathrm{mV}$ seemed to arise mainly from the putative delayed-rectifier conductance, with a very small contribution of the transient conductance (Fig. $5 B$ ). The total current at the end of the pulse from a holding voltage of $-50 \mathrm{mV}$, however, was less than that evoked from $-90 \mathrm{mV}$. As seen in Figure $5 C$, the subtracted currents were not 0 at the end of the $150-\mathrm{msec}$ pulse. This suggests either that the transient current has a slow inactivating component also, or that the late current shows a certain degree of voltage- and time-dependent inactivation. Four-sec-long depolarizing pulses, for example, showed that the total outward current reached a steady state only after about $1 \mathrm{sec}$ (see Laurent, 1990). It is not possible, at this stage, to assign this slowly decaying component to either of the transient or late outward currents. 

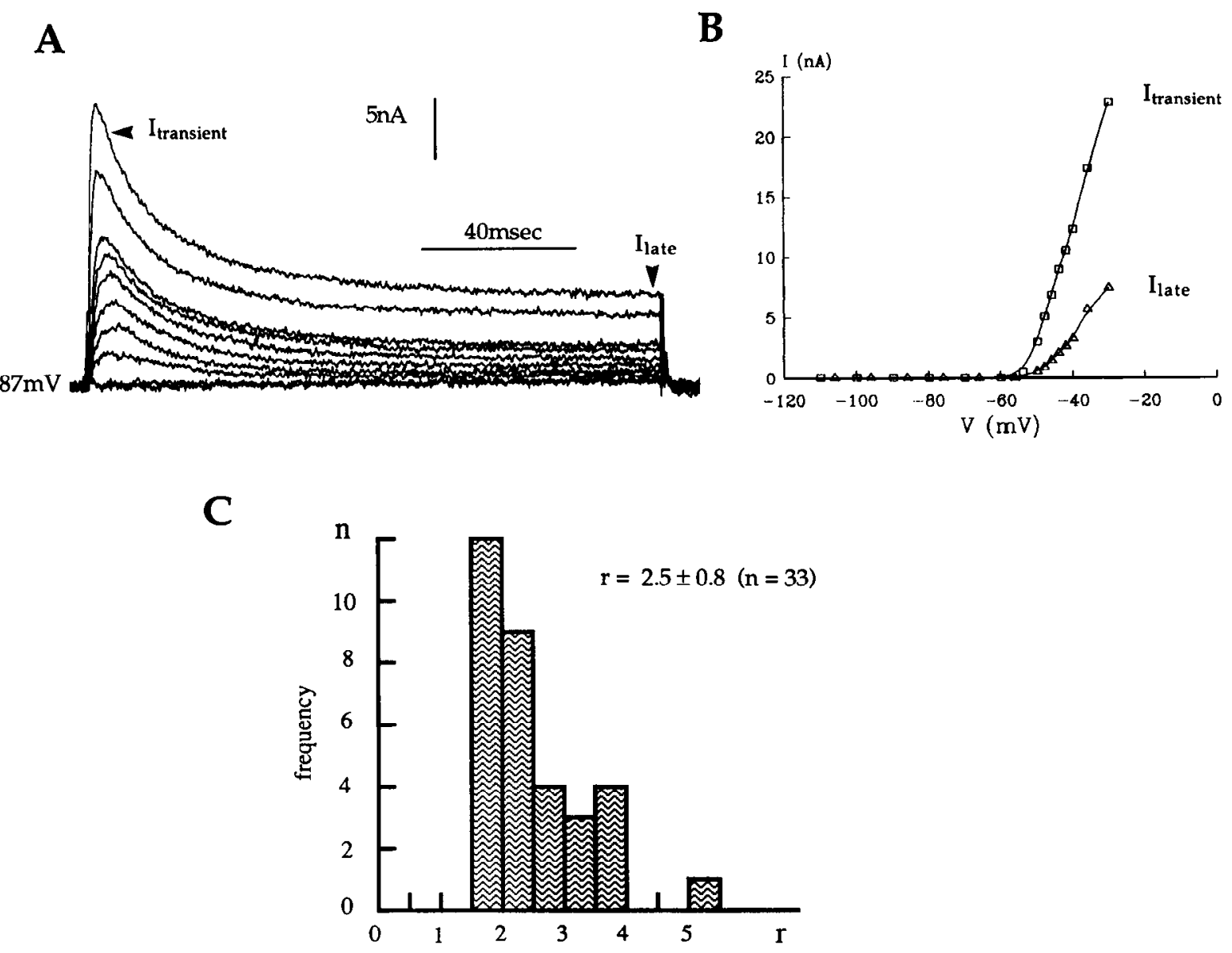

Figure 3. Activation of the outward currents. $A$, Voltage-activated currents after leak subtraction in a nonspiking local interneuron held at -87 $\mathrm{mV}$. Each trace is an average of eight traces. Temperature, $23^{\circ} \mathrm{C} ; \mathrm{SR}, 6.2 \mathrm{kHz} ; \mathrm{RP},-57 \mathrm{mV}$. Activation curves of the transient $\left(I_{\text {transient }}\right)$ and late $\left(I_{\text {late }}\right)$ currents measured, respectively, at the peak and at the end of the 150 -msec-long pulse in $A$. The data points at potentials more negative than $-85 \mathrm{mV}$ are assumed. $C$, Frequency distributions of the ratio $(r)$ of transient to late current in 33 interneurons. The measurements were made with currents generated by voltage steps of $+50 \mathrm{mV}$, from a holding potential of -90 to $-80 \mathrm{mV}$. The real values have been pooled in bins of 0.5 . Data are mean $\pm \mathrm{SD}$ ( $n$ of interneuron/recordings).

The fast decaying phase of the transient current could always be fit by a single exponential with an apparent time constant, $\tau$, of $8.1 \pm 1.6 \mathrm{msec}(n=8)$ at $-30 \mathrm{mV}$ (Fig. $5 D)$. This time constant did not show a strong voltage dependence in the range in which it was measured, though it increased slightly with less depolarization (Fig. 5D). The short value of this time constant suggested that maximum or at least significant currents would only be evoked during fast depolarizing events. Such consideration might be unimportant in some neurons, such as sympathetic neurons in the rat, where activation of an A-current can occur during the rising phase of an action potential (Beluzzi et al., 1985). In most locust nonspiking neurons, however, such rapid depolarizing events do not appear to exist, and activation of the transient current would presumably occur mainly during the rising or relaxation phase of slower synaptic events, due to spike-mediated or nonspiking synaptic transmission. The dependence of the transient outward current on the rate of depolarization was therefore studied during voltage-clamp ramps. Figure $6 A$ shows four depolarizing ramps delivered from a holding potential of $-80 \mathrm{mV}$ to final potentials of -60 to $-30 \mathrm{mV}$. The time from the onset to the end of the rising phase of each ramp was $30 \mathrm{msec}$. The four ramps in Figure $6 \mathrm{~A}$ thus differed both in their rate of depolarization and in their final voltage. During the initial portion of each ramp, the net current was outward, being the sum of the leak and capacitive components. Above a certain potential, the voltage-activated currents were activated, but only from an apparent threshold voltage of about $-45 \mathrm{mV}$ (Fig. $6 A$ ), that is, $15 \mathrm{mV}$ more depolarized than the value determined from voltage steps (see Fig. 3). In Figure $6 B$, six ramps to $-30 \mathrm{mV}$ were delivered, at depolarizing rates varying from 0.83 to $5 \mathrm{mV} / \mathrm{msec}$. For each rate of depolarization, the transient current (measured as the difference between total currents at the peak and at the end of the pulse) was normalized to the maximum current obtained during a voltage step (not shown). As the rate of depolarization decreased from 5 to $0.83 \mathrm{mV} / \mathrm{msec}$, the maximum transient current was reduced by more than $50 \%$ (Fig. $6 B, C$ ). The current recorded at the end of the 150-msec-long pulses, however, remained constant. The rate of depolarization thus seems to be critical for the transient current activation but not for the late one.

The activation time constant of the transient current was approximated by studying the time to peak during voltage steps from a holding potential of $-80 \mathrm{mV}$ (Fig. 7 , inset). This time to peak decreased from $\approx 11 \mathrm{msec}$ at $-50 \mathrm{mV}$ to less than 3 
A

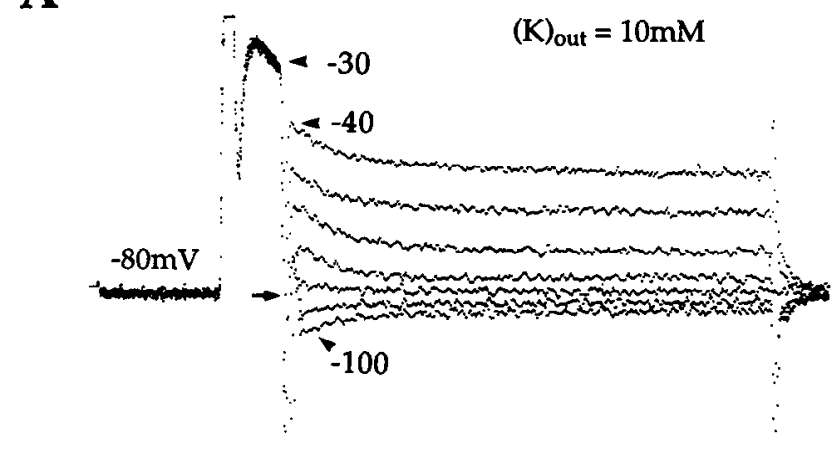

B

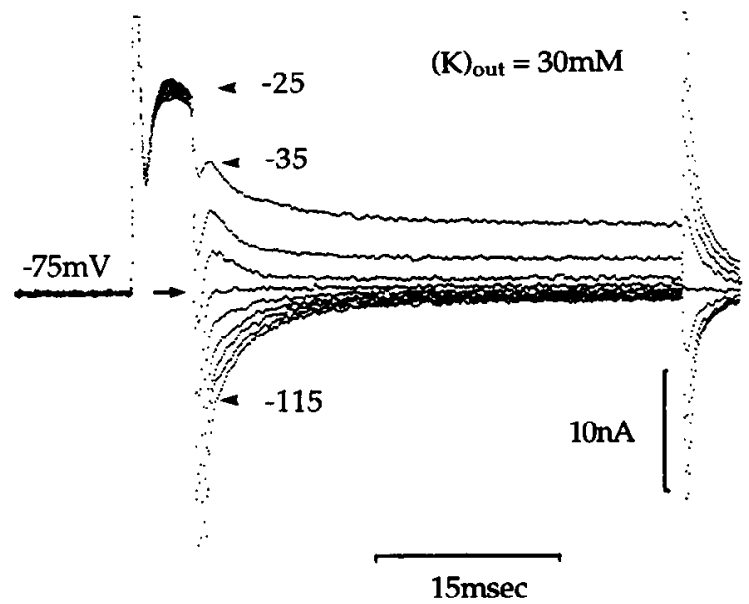

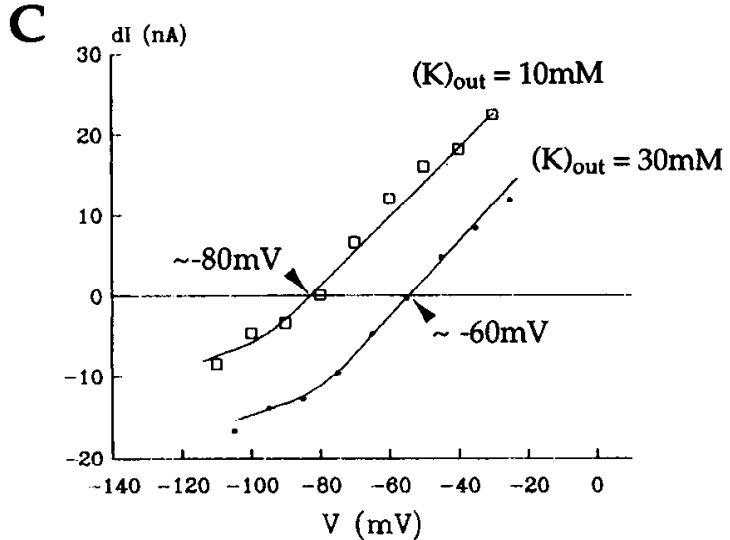

$\mathbf{D}$

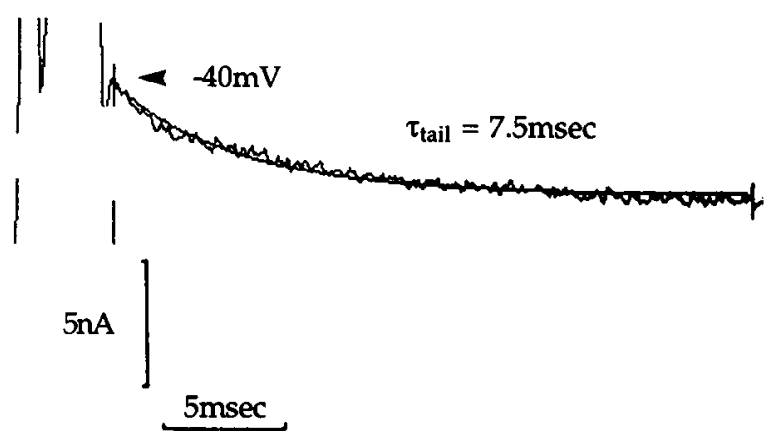

Figure 4. Reversal potential of the transient outward current. $A$, Results in $10 \mathrm{~mm} \mathrm{~K}_{\text {out }}$ (extracellular K) saline. The transient current was generated by a 4-msec step from -80 to $-30 \mathrm{mV}$. The membrane was then stepped back to voltages from -40 to $-100 \mathrm{mV}$. The tail current reversed around $-80 \mathrm{mV}$ (arrow). $B$, Results in $30 \mathrm{mM} \mathrm{K}_{\text {out }}$ saline, with same regime of stimulation as in $A$, but from a holding potential of $-75 \mathrm{mV}$. The reversal potential of the tail current is between -55 and $-65 \mathrm{mV}$ (arrow). Each trace is an average of four traces. $C$, Tail-current-voltage relationship for the two interneurons in $A$ and $B$. The shift of $\approx 20 \mathrm{mV}$ is less than that expected from the Nernst equation $[-58 \log (1 / 3)=27 \mathrm{mV}] . D$, The tail current evoked at $-40 \mathrm{mV}$ is fit by a single exponential with a time constant of decay of $7.5 \mathrm{msec}$ (same interneuron as in $A$ ). Temperature, $23^{\circ} \mathrm{C}$; SR, $6 \mathrm{kHz}$; RP, $-60 \mathrm{mV}$.

msec at $-20 \mathrm{mV}$ (Fig. 7). Note, however, that the accuracy of this measurement is limited by the single-electrode voltage clamp (see Materials and Methods).

\section{Steady-state inactivation of the transient outward current}

Nonspiking interneurons clamped at resting potential were stepped in a test pulse to -30 or $-10 \mathrm{mV}$ to evoke the transient outward current, after 1 -sec-long conditioning prepulses at potentials between -100 and $-20 \mathrm{mV}$, as shown in Figure $8 A$. For each trace, the late current was subtracted from the peak current, and the resulting value for the transient outward current was normalized as a fraction of the maximum current and plotted as a function of voltage (Fig. $8 B$ ). The data points obtained with four interneurons could be fit with a curve derived from the Boltzmann distribution:

$$
I / I_{\max }=\left\{1+\exp \left[\left(V-V_{1 / 2}\right) / k_{1 / 2}\right]\right\}^{1},
$$

where $I$ is the current evoked by a step from the conditioning voltage $V, V_{1 / 2}$ is the potential at which $I / I_{\max }=0.5$ (half-inactivation), and $k_{1 / 2}$ is a voltage-independent slope factor describing the steepness of the sigmoid curve. The mean values were $V_{1 / 2}$ $=-62 \mathrm{mV}$ and $k_{1 / 2}=7.5 \mathrm{mV}(n=4$ interneurons $)$. Given the possible underestimate of the maximum transient current, it is emphasized that this curve represents only the apparent steadystate inactivation.

\section{Time dependence of removal of inactivation}

Nonspiking interneurons were clamped at $V_{\text {rest }}-20 \mathrm{mV}$ and depolarized by $50 \mathrm{mV}$ for $100-300 \mathrm{msec}$. After each such prepulse, a test pulse of 50-msec duration was imposed, with interpulse delays varying between 5 and $300 \mathrm{msec}$. Pairs of such pulses were separated from each other by 2 sec. An example is shown in Figure $9 A$, where the prepulse delivered from a holding potential of $-80 \mathrm{mV}$ lasted $100 \mathrm{msec}$, and total recovery from inactivation was achieved within $200 \mathrm{msec}$. The ratio of peak to maximum current $\left(I / I_{\max }\right)$ was plotted for each test pulse against the corresponding interpulse delay (Fig. $9 B$ ). These points were well fit with a single exponential function of the form

$$
I / I_{\max }=1-e^{-t / \tau},
$$

where $I$ was measured as the difference between transient and late currents (the latter being measured at the end of a 300 msec-long pulse to the same command voltage). $\tau$ represents the time constant of removal of inactivation. This analysis re- 
The Journal of Neuroscience, June 1991, $11(6) 1719$

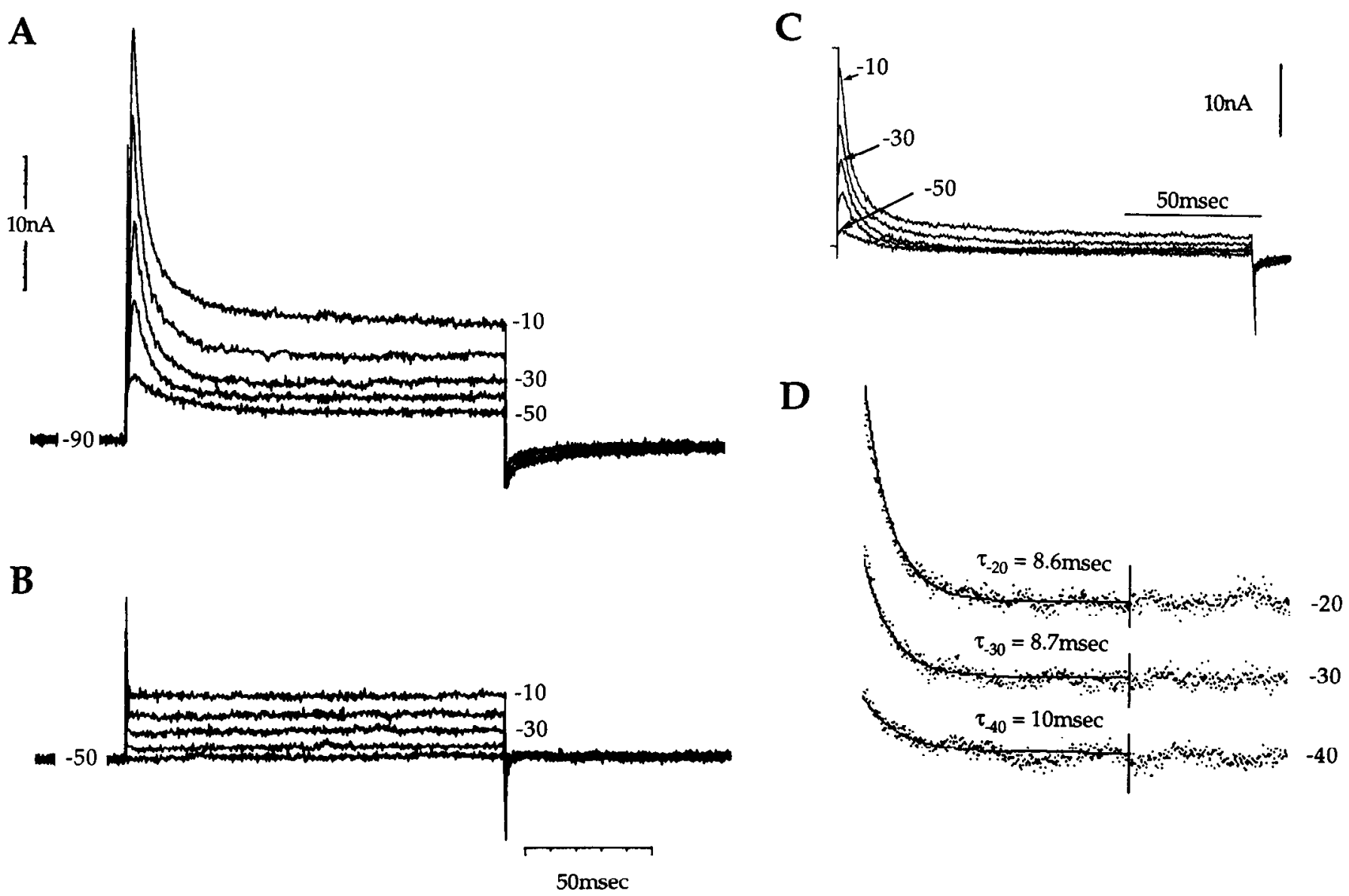

Figure 5. Separation of the transient and late currents. $A$, Outward currents evoked by depolarizing steps from a holding potential of $-90 \mathrm{mV}$ to $-50,-40,-30,-20$, and $-10 \mathrm{mV}$. Leak currents not subtracted. Temperature, $23^{\circ} \mathrm{C} ; \mathrm{SR}, 5.6 \mathrm{kHz} ; \mathrm{RP},-57 \mathrm{mV}$ (averages of four traces). $B$, Same interneuron as in $A$. Outward currents evoked by depolarizing steps from a holding potential of $-50 \mathrm{mV}$ to the same test voltages as in $A$ (leak not subtracted). $C$, Net currents, as obtained by subtracting corresponding traces of $B$ from those in $A$. $D$. Single exponential decay of the transient current at -40 to $-20 \mathrm{mV}$. Curve fitting is only performed with current traces from $6 \mathrm{msec}$ after onset of the voltage step. Temperature, $22^{\circ} \mathrm{C}$; SR, $6.6 \mathrm{kHz} ; \mathrm{RP},-65 \mathrm{mV}$.

vealed that, in all cases, the recovery followed a single exponential time course, but that the time constant of recovery depended on the duration of the prepulse. Whereas a $100-\mathrm{msec}-$ long prepulse led to a time constant of recovery of $50 \mathrm{msec}$ at $-80 \mathrm{mV}$ (probably reflecting an only partial inactivation by the short prepulse), a 300-msec-long prepulse led to a time constant twice as long (Fig. 9B). Longer prepulses did not lead to longer time constants of recovery. Recovery from inactivation of the transient outward current was well correlated with recovery from inactivation of the transient outward rectification observed in current-clamp recording. The nonspiking interneuron in Figure 10 was held at a resting potential of about $-60 \mathrm{mV}$ and depolarized in paired current pulses, following a regime similar to that used in the above voltage-clamp experiments. Transient outward rectification was absent from the onset of the second pulse (test pulse) when the delay between conditioning pulse and test pulse was only $5 \mathrm{msec}$ (Fig. 10A). It reappeared gradually as the delay between prepulse and test pulse was increased (Fig. 10B-D).

\section{Effects of $K^{+}$channel blockers and cobalt ions}

TEA at a bath concentration of $10 \mathrm{~mm}$ led to a reduction of both transient and late outward currents. In the interneuron shown in Figure $11 A$, the maximum slope conductance of the transient outward current decreased by $70 \% 15 \mathrm{~min}$ after the application of TEA, whereas that of the late current decreased by $60 \%$ (Fig. $11 \mathrm{~B}$ ). In none of the experiments in which TEA was applied (at either 5 or $10 \mathrm{~mm}$ ) could penetration and stable recording be maintained long enough to test the reversibility of this effect. In no case could the late current be partially blocked withou't also affecting the transicnt current. 4-AP at a bath concentration of $1 \mathrm{mM}$ had no effect on either current. At $5 \mathrm{~mm}$, 4-AP blocked the transient outward current most effectively in two interneurons out of five tested, but not without also affecting the late current, though to a lesser extent (Fig. 11C). It is possible that the late component of the blocked outward current represents a slowly inactivating component of the transient current. In the interneuron in Figure $11 \mathrm{C}$, the maximum slope conductance of the transient current was reduced by $85 \%$, and that of the late current, by $14.5 \%$ (Fig. $11 D$ ). Here, too, the reversibility of the effect could not be tested. In the other three interneurons, no significant effect was observed. Quinidine at a bath concentration of $100 \mu \mathrm{M}$ was found ineffective on either current (not shown). The blocking effects of TEA and 4-AP on the outward currents were supported by current-clamp experiments in which TEA and 4-AP were shown to reduce the outward rectification. 


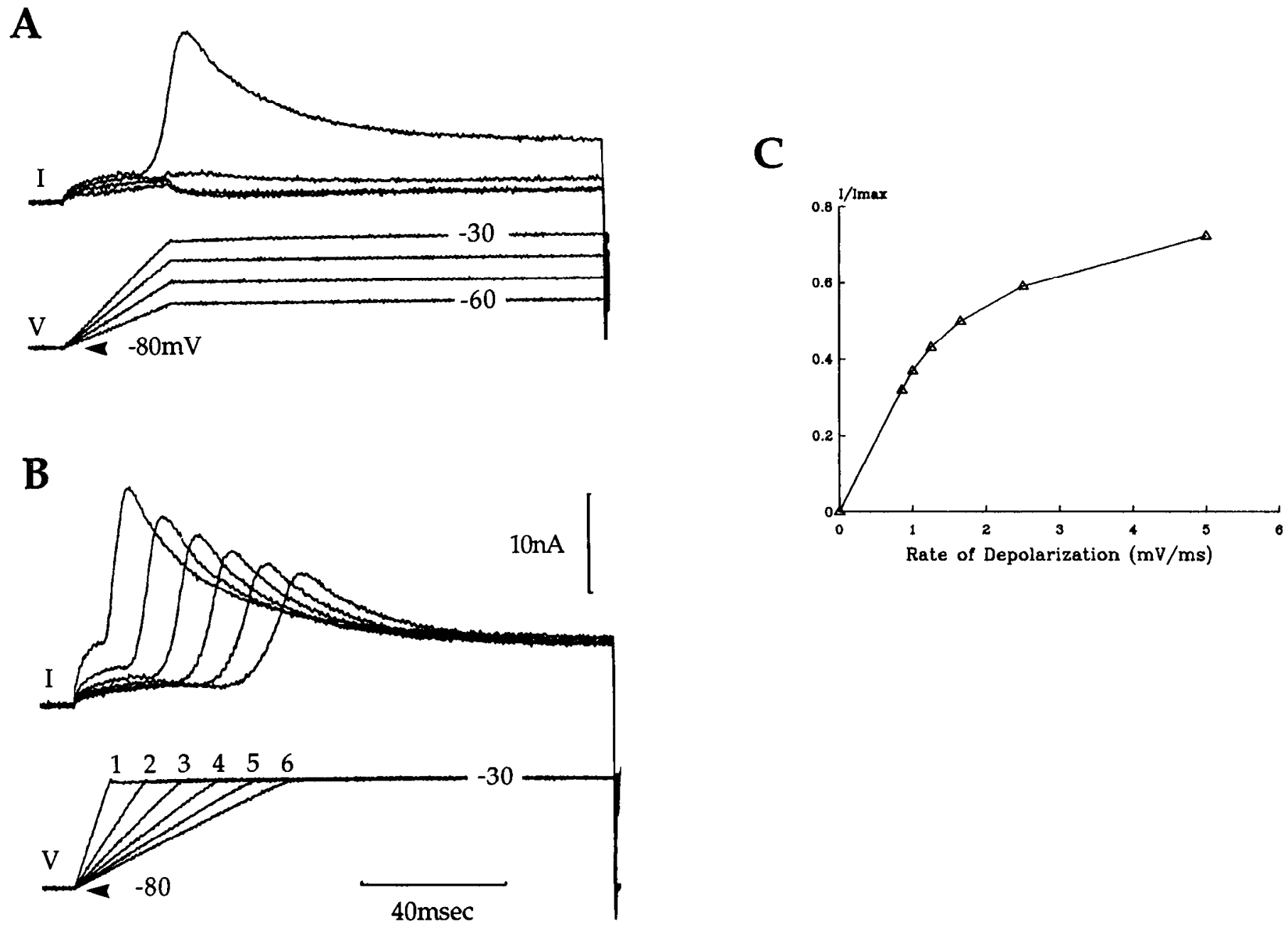

Figure 6. Activation of the outward currents during ramp depolarizations. A, Ramp depolarizations from $-80 \mathrm{mV}$ to $-60,-50,-40$, and -30 $\mathrm{mV}$. Leak and capacitive components are seen during the ramps. $B$, Ramp depolarizations from -80 to $-30 \mathrm{mV}$ at the following rates: $1,5 \mathrm{mV} /$ $\mathrm{msec} ; 2,2.5 \mathrm{mV} / \mathrm{msec} ; 3,1.65 \mathrm{mV} / \mathrm{msec} ; 4,1.25 \mathrm{mV} / \mathrm{msec} ; 5,1 \mathrm{mV} / \mathrm{msec} ; 6,0.83 \mathrm{mV} / \mathrm{msec}$. Note the decrease in transient current as the rate of depolarization decreases and the constant steady state at the end of the pulse (same interneuron as in $A$; averages of eight traces). Note the good control of membrane voltage. $C$, Plot of the ratio of transient to maximum current as a function of rate of depolarization (data in $B$ ). Temperature, $24^{\circ} \mathrm{C}$; SR, $6.2 \mathrm{kHz} ; \mathrm{RP},-60 \mathrm{mV}$.

The interneuron in Figure 12 was depolarized from a "resting" potential of $-65 \mathrm{mV}$ by injection of an 8-nA current pulse. During the control pulse in normal saline, the outward rectification led to a rapid plateauing of potential, only $10 \mathrm{mV}$ more positive than "resting" potential. This was accompanied by an increase in input conductance, leading to a decrease in the membrane time constant and a "shunting" of the tonic IPSPs (Fig. $12 i$, control). Fifteen minutes after perfusion of $10 \mathrm{~mm}$ TEA and $2 \mathrm{~mm}$ 4-AP, the same current pulse evoked a large depolarization of about $30 \mathrm{mV}$ at steady state, during which the size of the tonic IPSPs was increased, as would be expected from the increased driving force. The time constant of decay of the IPSPs then was not greatly shortened (Fig. 12ii). These effects are well explained by the reduction of the outward currents due to TEA and 4-AP, leading to a reduction of the conductance increase caused by the depolarizing step.

Finally, the dependency of the outward currents on extracellular $\mathrm{Ca}^{2+}$ was studied by using extracellular $\mathrm{Co}^{2+}$, a known $\mathrm{Ca}^{2+}$ conductance blocker, at a bath concentration of $25 \mathrm{~mm}$. Neither of the two outward currents seemed to be affected by $\mathrm{Co}^{2+}$ ions (not shown). The effect of $\mathrm{Ca}^{2+}$ removal was not studied because a significant decrease in the neuropilar extracellular $\mathrm{Ca}^{2+}$ concentration would have required a time longcr than that for which intracellular penetration could be maintained (see Discussion).

\section{Discussion}

The present results demonstrate that voltage-activated membrane currents of well-characterized insect interneurons can be studied in situ, in an intact nervous system, and from neuropilar recordings. This is significant because the soma membrane, from which most voltage-clamp studies have so far been carried out, plays no integrative role in invertebrate central neurons. One clear indication that soma and neuropilar membranes differ is the fact that no active spikes can be recorded from the cell body of nearly all known locust spiking neurons. To understand the integrative function of voltage-gated membrane conductances, it is therefore important to focus on those regions of the neuron membrane that process synaptic information. The single-electrode voltage-clamp technique applied to intact neurons, however, suffers from several limitations. First, "adequate" space 


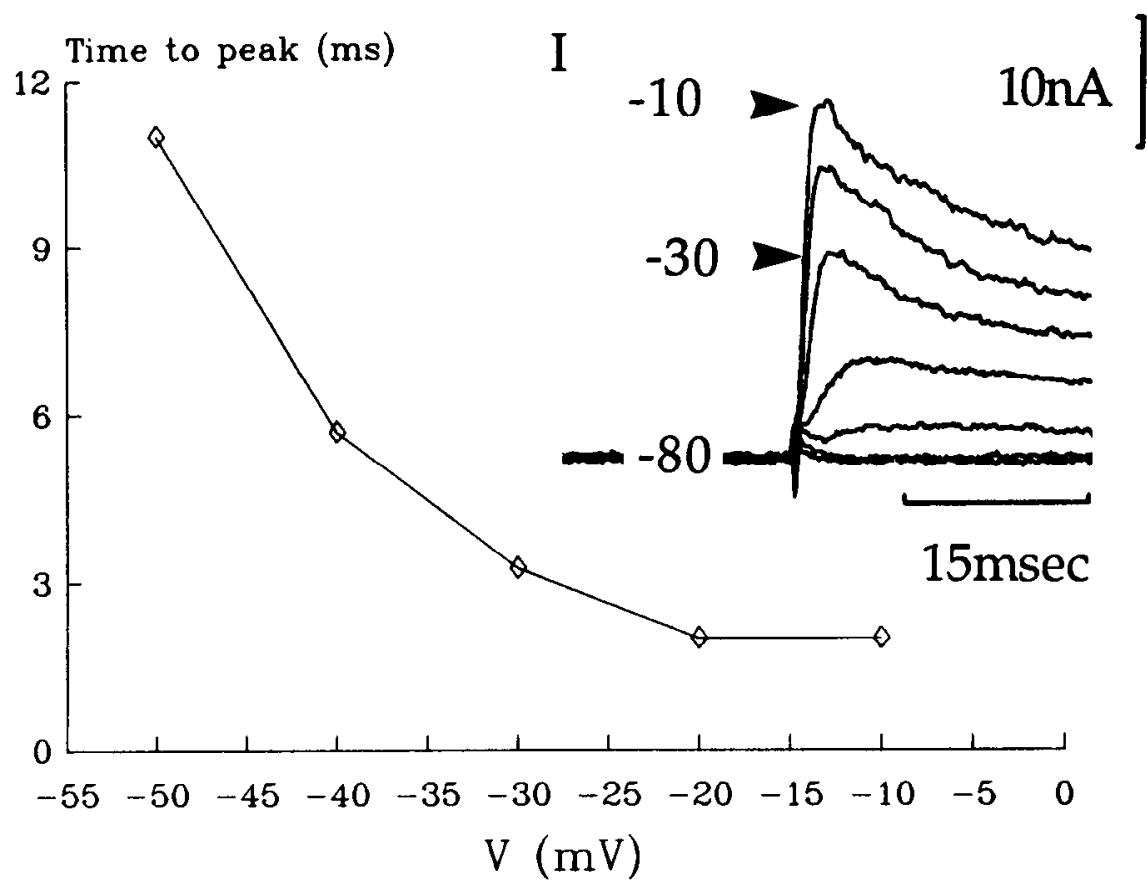

Figure 7. Time to peak of transient outward current for pulses delivered from a holding potential of $-80 \mathrm{mV}$. Traces in the inset are leak subtracted and are averages of four traces. Temperature, $26.6^{\circ} \mathrm{C} ; \mathrm{SR}, 6.2 \mathrm{kHz}$; RP, -60 $\mathrm{mV}$. The measurements of time to peak at -30 to $-10 \mathrm{mV}$ are subject to error, due to the speed limitations of the single-electrode voltage clamp.

clamp was obtained in only $13 \%$ (36 of 272 ) of the recordings. This is not surprising, given the size and complex branching patterns of locust nonspiking interneurons (Siegler and Burrows, 1979; Watkins et al., 1985). It is possible that acceptable recording conditions occurred when the electrode tip was inside a relatively small and unbranched process, separated from the rest of the neuron by a high-axial-resistance pathway such as a narrow constriction (for electron microscopy, see Watson and Burrows, 1988). Even in such conditions, however, the settling of the capacitive current was never simultancous to the stabilization of the membrane potential in the vicinity of the electrode. Second, the limited speed and gain of the single-electrode clamp added to the spatial considerations prevented any attempt to control the membrane potential during fast regenerative events such as action potentials in spiking neurons (G. Laurent, unpublished observations). For the same reasons, the activation characteristics of rapidly developing currents, such as the transient outward current described here, could only be approximated, and all quantitative results are thus as yet only indicative. Third, because of the tight structure of the insect neuropil and surrounding blood-brain barrier, penetration of pharmacological agents or control of extracellular ionic concentrations were limited and uncertain. The results presented here therefore constitute an initial and mainly qualitative attempt to characterize
A

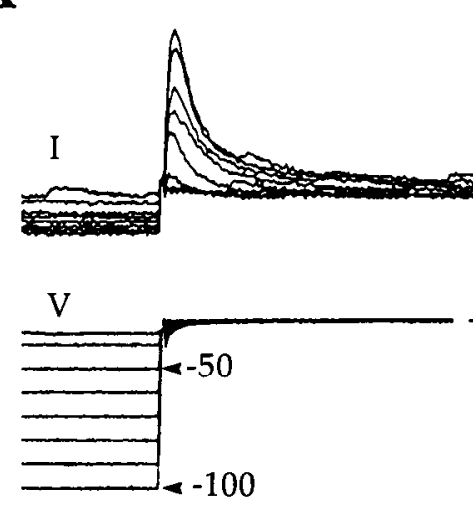

B

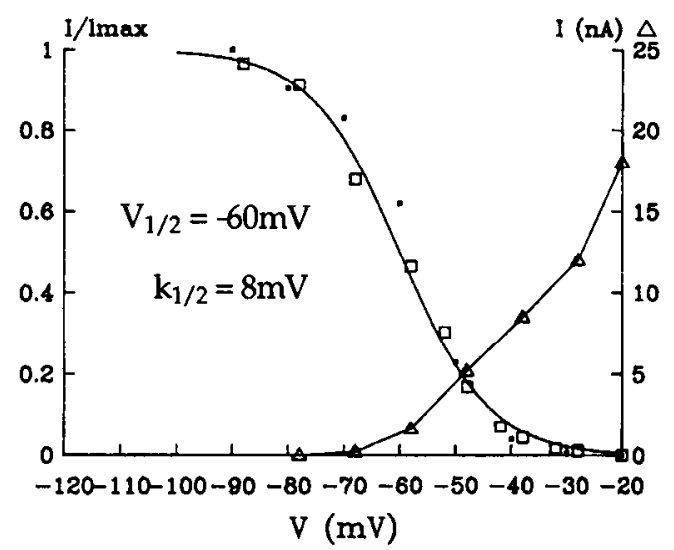

Figure 8. Steady-state inactivation of the transient outward current. $A$, The membrane is conditioned to voltages of -100 to $-35 \mathrm{mV}$ during 1 -sec-long prepulses before being stepped to $-30 \mathrm{mV}$ for $150 \mathrm{msec}$. IPSC, inhibitory postsynaptic current, probably generated by inputs from tonically active presynaptic spiking local interneurons. Temperature, $20.9^{\circ} \mathrm{C} ; \mathrm{SR}, 6 \mathrm{kHz} ; \mathrm{RP},-60 \mathrm{mV}$ (leak subtracted). $B$, Inactivation of two interneurons (different from that in $A$ ) in $S$. gregaria (open squares) and $S$. americana (solid squares), fit by a curve derived from the Boltzmann distribution. $V_{1 / 2}$, voltage of half-inactivation; $k_{1 / 2}$, slope factor. The activation curve for the interneuron whose inactivation is plotted with open squares is represented (open triangles) to show the overlap of the activation and inactivation curves around $-50 \mathrm{mV}$. 

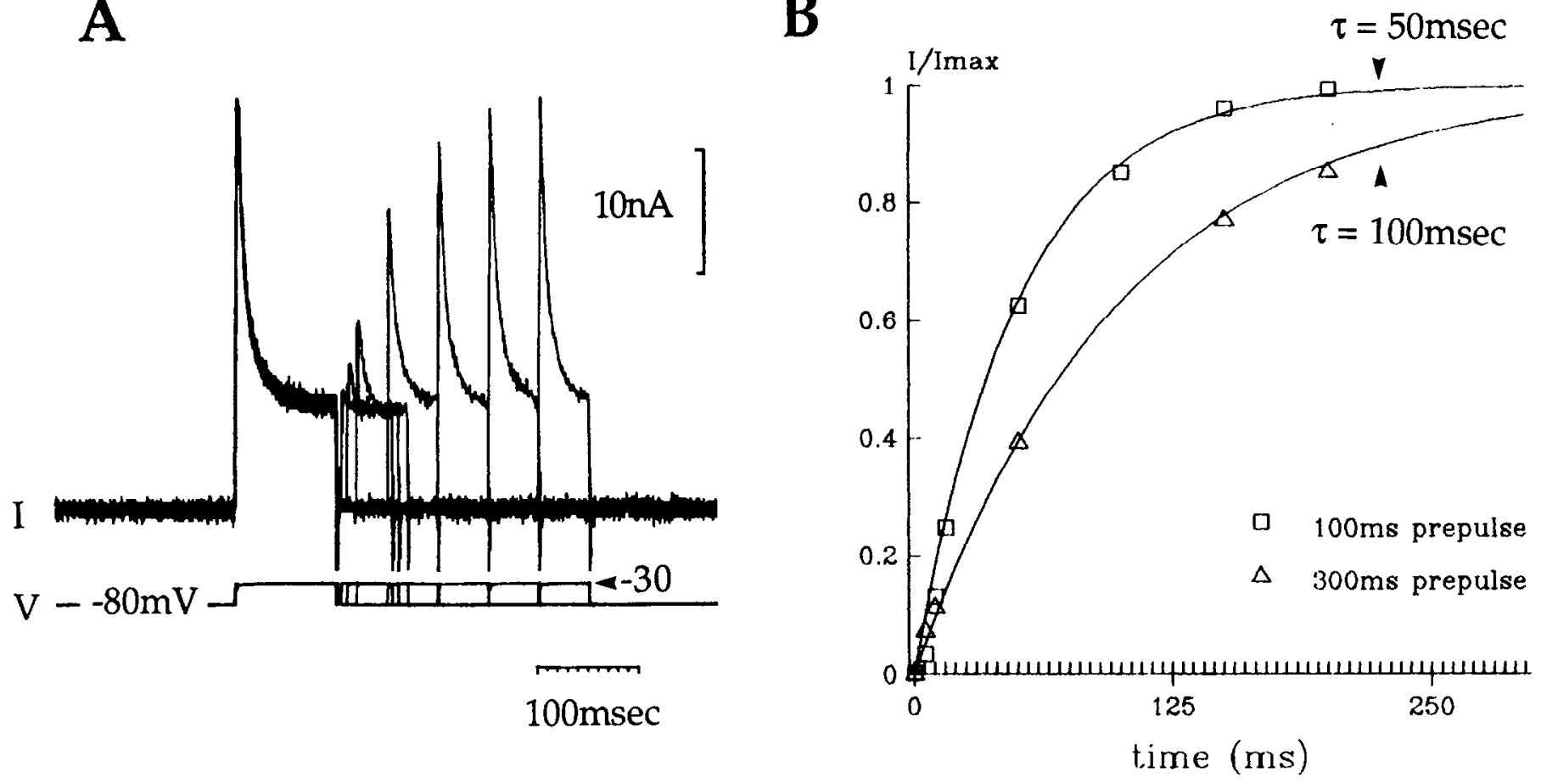

Figure 9. Recovery from inactivation of the transient outward current. $A$, A 100 -msec-long depolarizing pulse from -80 to $-30 \mathrm{mV}$ is delivered and followed, after a varying delay, by a second and shorter pulse to the same potential. Total recovery occurs within $200 \mathrm{msec}$. Temperature, $24^{\circ} \mathrm{C}$; SR, $6.2 \mathrm{kHz} ; \mathrm{RP},-50 \mathrm{mV}$ (leak not subtracted). $B$, Plot of $I / I_{\max }$ of interneuron in $A$ against the duration of the interpulse delay. Open squares, 100-msec prepulse; open triangles, 300-msec prepulse. Recovery in each case is well fit by a single exponential time course (see Results).

membrane currents in nonspiking interneurons, before further work on dissociated cells in culture can be undertaken and the results from such investigations given any functional interpretation.

\section{Functional considerations}

Nonspiking local interneurons appear to be an essential component of the sensory-motor pathways in locust thoracic ganglia
Figure 10. Recovery from inactivation of transient outward rectification. Double pulse depolarizations $(+5 \mathrm{nA})$ are delivered to a nonspiking interneuron from a resting potential of $-57 \mathrm{mV}$. Interpulse delay increases from $A$ to $D$. Transient outward rectification is absent in the second pulse in $A$ but reappears gradually as the delay increases. Each pair of pulses is separated from the next by 2 sec. Note the dramatic shunting of IPSPS and the decrease in their time constant of decay during the current pulses, due to outward rectification and increase in input conductance. Temperature, $23^{\circ} \mathrm{C} ; \mathrm{SR}, 5.4 \mathrm{kHz}$. The dotted line indicates the voltage from which the slow depolarization occurs.

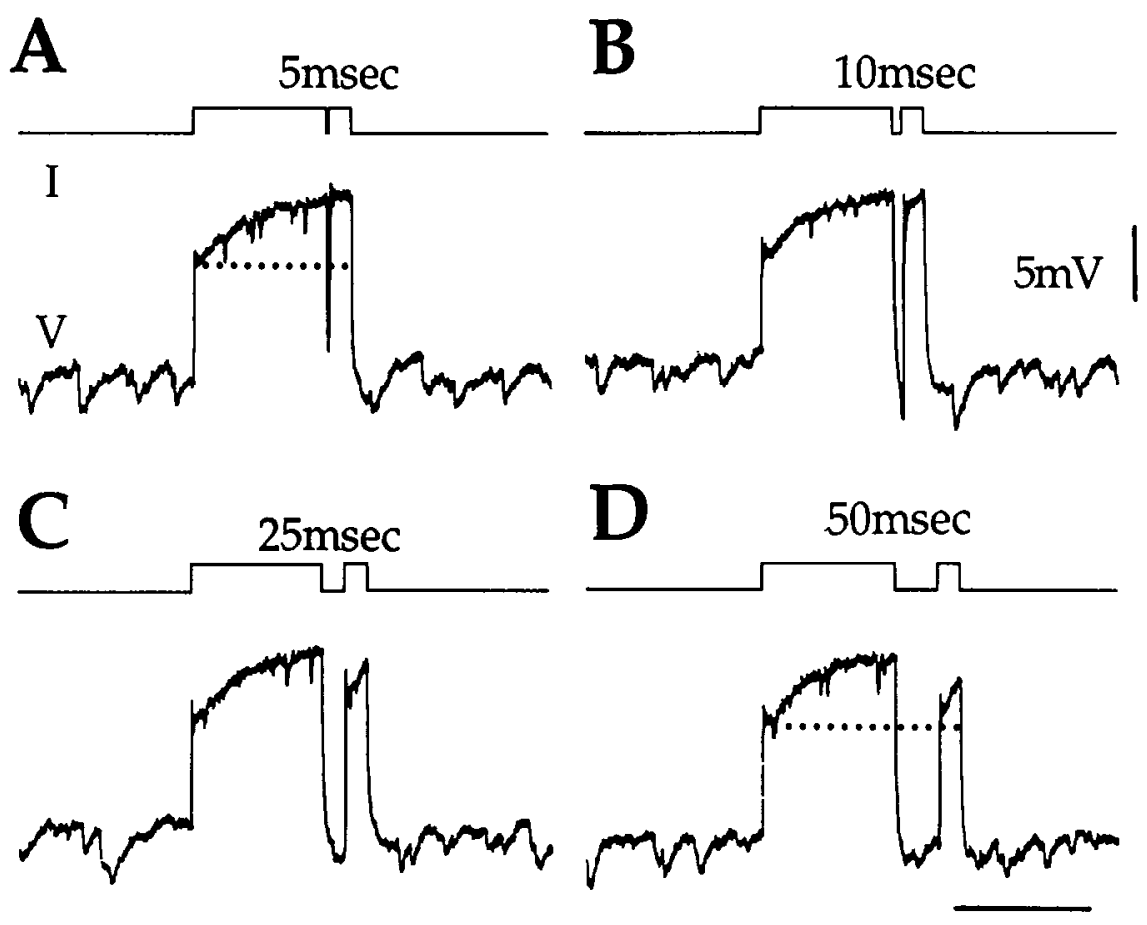


A
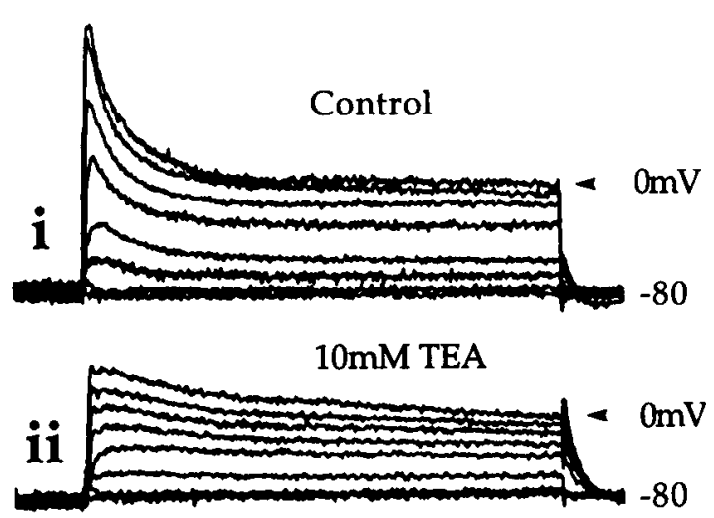

$50 \mathrm{msec}$
B

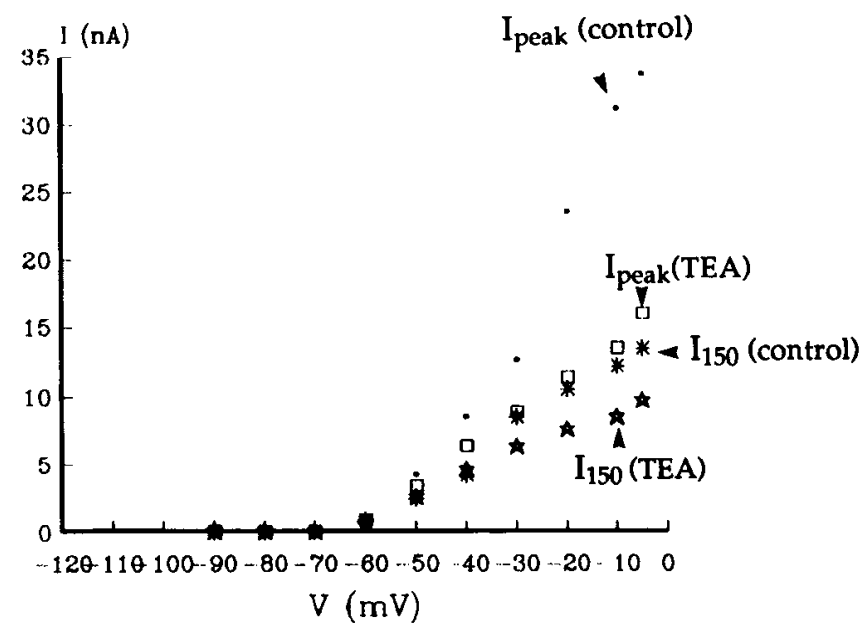

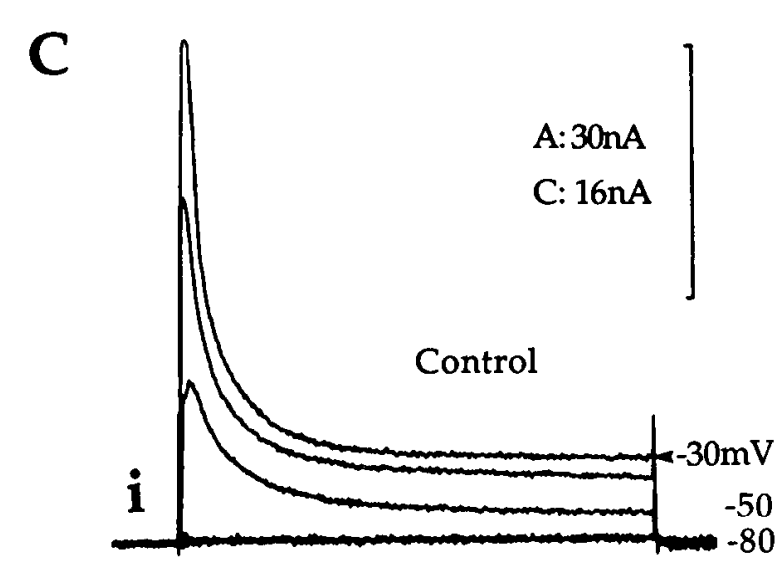

5MM 4-AP

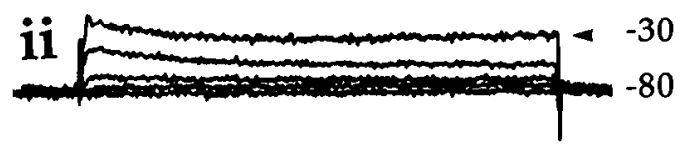

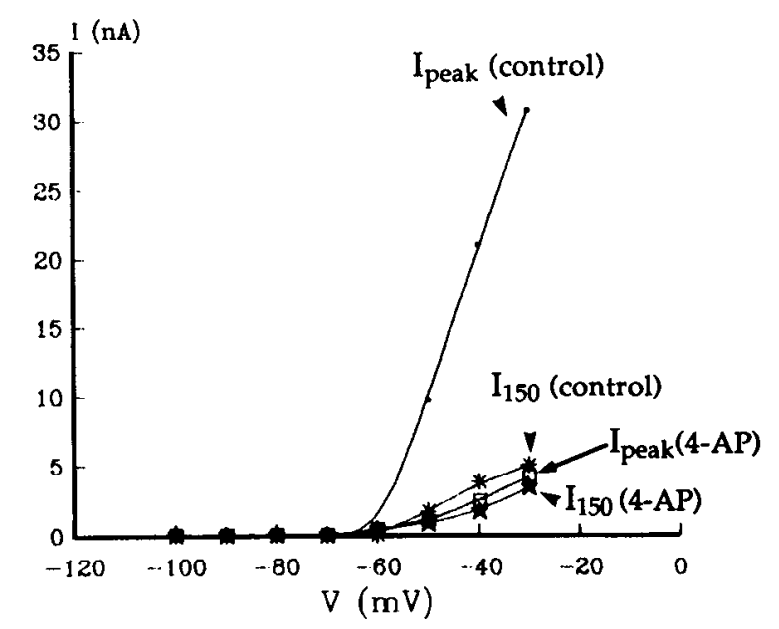

Figure 11. Effects of $10 \mathrm{mM}$ TEA $(A i i, B)$ and $5 \mathrm{~mm} \mathrm{4-AP}(C i i, D)$ on transient $\left(I_{\text {peak }}\right)$ and late $\left(I_{I 50}\right.$, measured at the end of each 150 -msec-long pulse) currents. Currents in $A i, i i$, and $C i, i i$ are leak subtracted. The currents measured in $A$ and $C$ are plotted against membrane voltage in $B$ and $D$, respectively. Traces are averages of eight traces in $A$ and $C . A$, Temperature, $26.8^{\circ} \mathrm{C} ; \mathrm{SR}, 6.1 \mathrm{kHz} ; \mathrm{RP},-60 \mathrm{mV} . C, \mathrm{Temperature}, 26.3^{\circ} \mathrm{C} ; \mathrm{SR}$, $6.5 \mathrm{kHz} ; \mathrm{RP},-50 \mathrm{mV}$.

(Burrows and Laurent, 1989). On them converge inputs from mechanosensory afferents (Burrows et al., 1988; Laurent and Burrows, 1988), spiking and nonspiking local interneurons (Burrows, 1979, 1987), and intersegmental interneurons (Laurent and Burrows, 1989a,b). The graded signals they process and then transmit to motor neurons (Burrows and Siegler, 1978) are shaped by the cell membrane capacitance, the branching geometry, the relative distribution of input and output synapses, and the nature of the synaptic and voltage-activated conductances borne by the membrane. It is thus important to relate the function of these various parameters to the computations that these neurons perform. It will be important, for example, to determine if, like in the retinal nonspiking neurons of ver- tebrates and invertebrates (Kaneko and Tashibana, 1985; Hardie and Weckström, 1990; Hardie et al., 1991), voltage-gated currents serve to enhance or suppress certain desirable or undesirable temporal frequencies of the input. Because nonspiking local interneurons receive both spike-mediated and graded/tonic synaptic inputs, such differential filtering could occur. In particular, one would like to know if the variability in the ratio of transient to late current reflects a difference between individual interneurons, or rather between recording sites within the branches of these interneurons. In the latter case, heterogeneity in the $\mathrm{K}^{+}$channel distribution might become crucial in local dendritic computations.

Are the outward currents responsible for the nonexcitable prop- 


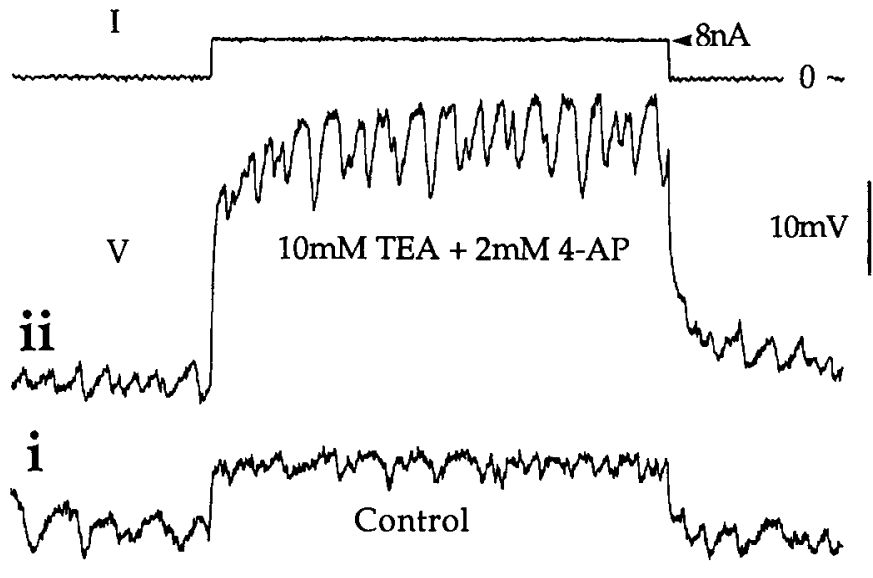

$200 \mathrm{msec}$

Figure 12. Effect of $\mathrm{K}^{+}$channel blockers on outward rectification and on the reduction of postsynaptic potential amplitude and time constant of decay during depolarization. $i$, The membrane was stepped by $+8-$ nA current pulse injection in current-clamp mode. Note the reduction in amplitude and time constant of decay of IPSPs during the control pulse. $i i$, Fifteen minutes after perfusion of $10 \mathrm{~mm}$ TEA and $2 \mathrm{~mm} 4-\Lambda \mathrm{P}$, the same current pulse was delivered. Note the reduction of the outward rectification and the increase in amplitude of the IPSPs during the pulse. Temperature, $26.3^{\circ} \mathrm{C}$; SR, $6.6 \mathrm{kHz} ; \mathrm{RP},-65 \mathrm{mV}$.

erties of the interneurons? In the dendrite of the crab " $T$ "-fiber, a nonspiking sensory receptor found in the legs of crustaceans (Ripley et al., 1968), a fast outward current may account for the nonexcitability of the membrane, by shunting a relatively small inward current, carried by a low density of $\mathrm{Na}^{+}$channels (Mirol$\mathrm{li}, 1981,1983)$. The existence of a fast $\mathrm{Na}^{+}$current in the membrane of locust nonspiking interneurons is unlikely, however, because large depolarizations to about $-30 \mathrm{mV}$ in the presence of extracellular TEA and 4-AP failed to reveal any fast regenerative properties during current-clamp recording, even after a prolonged hyperpolarization. Although voltage clamp of fast $\mathrm{Na}^{+}$spikes would have not been possible, large depolarizing steps would have nevertheless revealed unclamped spikes generated remotely, as was always observed when recording from spiking neurons (Laurent, unpublished observations). Such events were never revealed.

Are the outward-current activation and inactivation properties within the operating range of the interneurons? Current-clamp data showed that nonspiking interneurons rectify during depolarization, and that the outward rectification starts from potentials 10-20-mV more negative than "resting" potential (Laurent, 1990). Below about $-75 \mathrm{mV}$, the current-voltage relationship is ohmic. The activation curves of the total currents presented here show that the outward currents activate from about $-60 \mathrm{mV}$, that is, only slightly more negative than rest. There thus seems to be a slight mismatch between the currentclamp and voltage-clamp data, the reason for which is not yet understood. At potentials more positive than about $-65 \mathrm{mV}$, however, the conductance increase due to the voltage-gated currents can account for the drop in neuron input resistance and membrane time constant observed in current clamp (Laurent, 1990). Despite the lack of data on the activity of nonspiking interneurons during locomotion, it seems nevertheless that they normally operate between potentials of -60 and $-35 \mathrm{mV}$, judg- ing from the range of membrane potentials sampled in intact animals (Pearson and Fourtner, 1975; Burrows and Siegler, 1978). Nonspiking local interneurons in the crab ventilatory system also operate in a comparable range of potentials, between -53 and $-31 \mathrm{mV}$ (DiCaprio, 1989). The fact that the transient outward current in locust nonspiking interneurons appears only half-inactivated at $-60 \mathrm{mV}$ indicates that this current could be activated from resting potential. This is important, because nonspiking interneurons cannot, by definition, rely on the afterhyperpolarization following an action potential, for example, to remove the transient current from inactivation, as in most other neurons where an A-current has been found (Rogawski, 1985). Whether the membrane potential of nonspiking interneurons ever reaches values negative enough to remove inactivation totally, however, is unknown. Recording from nonspiking interneurons in walking animals will hopefully help to resolve this issue.

\section{Identification of the outward currents}

The transient outward current was carried at least partly by potassium ions, activated by depolarization from about -60 $\mathrm{mV}$, and half-inactivated at about $-60 \mathrm{mV}$. The activation and inactivation curves thus overlap above $-60 \mathrm{mV}$. Current inactivation was rapid and followed at least one exponential time course with a shorter time constant of $\approx 10 \mathrm{msec}$, which appeared independent of voltage in the range tested. Recovery from inactivation followed a single exponential time course, with a time constant of $\approx 100 \mathrm{msec}$. Finally, this current was, in certain cases, sensitive to extracellular application of 4-AP at millimolar concentration. The reason why 4-AP was only effective in a few neurons may be that 4-AP acts best when it has access to the intracellular side of the membrane (Hermann and Gorman, 1981; Kros and Crawford, 1990). Such a condition could have occurred only in those cases where the membrane was injured or when 4-AP, which is partially membrane permeant, had good access to the membrane of the interneurons. These features are reminiscent of the A-current, first described in invertebrate neurons (Hagiwara et al., 1961; Connor and Stevens, 1971; Neher, 1971) and now known in amphibian, avian, and mammalian neurons also (see Bader ct al., 1985; Rudy, 1988; Florio et al., 1990). A-currents in insects have been well characterized in Drosophila nervous system and muscle. There, the two subtypes $A_{1}$ and $A_{2}$, characterized in muscle and in embryonic neurons, respectively, show different activation and inactivation properties and single-channel conductances (Solc et al., 1987; Solc and Aldrich, 1988; Zagotta et al., 1988). The transient outward current in locust nonspiking local interneurons resembles most the Drosophila neuronal $\mathrm{A}_{2}$ subtype, which is activated by depolarization around -60 to $-55 \mathrm{mV}$, and has a comparably short time constant of inactivation. Its steady-state inactivation curve, however, appears shifted to more positive values in locust nonspiking interneurons. This feature is functionally relevant because nonspiking neurons are generally less polarized at rest than spiking neurons (Burrows and Siegler, 1978; Laurent, 1990). The presence of a slowly inactivating phase following the fast relaxation of the transient current could not be assigned to either of the transient or late components. $I_{\mathrm{A}_{2}}$ in Drosophila, for example, decays in two exponential phases, the slower of which has a time constant of 60-300 msec (Solc and Aldrich, 1988), commensurate with the present observation in the locust.

The results of Byerly and Leung (1988) indicate that part of 
the total voltage-dependent currents activated by depolarization in Drosophila neurons depend on extracellular $\mathrm{Ca}^{2+}$. They suggest, however, that only the sustained component is $\mathrm{Ca}^{2+} \mathrm{de}-$ pendent. This is consistent with the observation that the $\mathrm{A}_{2}$ channels do not seem to be affected by external $\mathrm{Cd}^{2+}, \mathrm{Co}^{2+}$, or 0 -miм Ca ${ }^{2+}$ (Solc and Aldrich, 1988). In Drosophila muscle, however, both the transient and the sustained voltage-activated $\mathrm{K}^{+}$currents appear to have corresponding fast and slow $\mathrm{Ca}^{2+}$ dependent components (Salkoff, 1983; Singh and $\mathrm{Wu}, 1989$ ). The dependence on extracellular $\mathrm{Ca}^{2+}$ of the transient outward current described here in locust nonspiking interneurons is not well known. Studying neurotransmission at a central locust synapse, Burrows et al. (1989) found that only after $50 \mathrm{~min}$ of $0-\mathrm{mm}$ $\mathrm{Ca}^{2+}$ saline perfusion could a $50 \%$ reduction of a postsynaptic potential amplitude be observed. This very slow effect illustrates the efficacy of the locust blood-brain barrier and prevented any attempt to test the effect of extracellular $\mathrm{Ca}^{2+}$ removal on the outward currents, while maintaining stable neuropilar penetration of nonspiking interneurons. The absence of effect of $\mathrm{Co}^{2+}$ ions, however, tends to suggest that the two outward currents do not depend strongly on extracellular $\mathrm{Ca}^{2+}$.

The existence in $15 \%$ of the interneurons of an additional slowly developing and inactivating outward current (see Fig. $2 B$ ) adds to the complexity of nonspiking neuron membrane properties. Preliminary experiments with these interneurons suggest that the second peak outward current evoked by depolarization is preceded by a moderately slow inward current, whose charge carrier is as yet unidentified (Laurent, unpublished observations). It is possible that these two currents are a $\mathrm{Ca}^{2+}$ current and a $\mathrm{Ca}^{2+}$-dependent $\mathrm{K}^{+}$current, and that they are responsible for the membrane-potential oscillations or the slow regenerative potentials sometimes observed in current clamp. The possibility that these oscillations are due to feedback through synaptic interactions with connected neurons exists, but appears remote, because all known output connections made by locust nonspiking interneurons are nonreciprocal.

The late outward current could be maintained for several seconds (up to $4 \mathrm{sec}$ tested) without showing any decline after the end of the first $1-1.5 \mathrm{sec}$ of a depolarizing pulse. This is consistent with the finding that the membrane of nonspiking interneurons is not in a passive state at resting potential (Laurent, 1990). This current was partially blocked by TEA applied extracellularly at concentrations of 5-10 mM. Its apparent sensitivity to 4-AP was possibly artifactual, because the current reduction measured at the end of 150 -msec-long pulses may in fact only have represented the slowly inactivating component of the transient current (see above). On the other hand, $\mathrm{K}^{+}$ channels sensitive to both TEA and 4-AP have been described in mammalian cells (Ypey and Clapham, 1984; Hoshi and Aldrich, 1988). The late component of the outward current thus appears similar to the delayed-rectifier current (Hodgkin and Huxley, 1952), named $I_{\mathrm{K}}$ or $I_{\mathrm{KD}}$ in Drosophila neuron or muscle (Solc and Aldrich, 1988; Singh and Wu, 1989). It is thus proposed that both A-type and delayed-rectifier potassium channels are present in the neuropilar membrane of nonspiking local interneurons.

\section{References}

Bader CR, Bertrand D, Dupin (1985) Voltage-dependent potassium currents in developing neurones from quail mesencephalic neural crest. J Physiol (Lond) 366:129-151.

Beluzzi O, Sacchi O, Wanke E (1985) A fast transient outward current in the rat sympathetic neurone studied under voltage-clamp conditions. J Physiol (Lond) 358:91-108.

Burrows M (1979) Synaptic potentials effect the release of transmitter from locust nonspiking interneurons. Science 204:81-83.

Burrows M (1987) Inhibitory interactions between spiking and nonspiking local interneurons in the locust. J Neurosci 7:3282-3292.

Burrows M, Laurent G (1989) Reflex circuits and the control of movement. In: The computing neuron (Durbin R, Miall RC, Mitchison G, eds), pp 244-261. Reading, MA: Addison-Wesley.

Burrows M, Siegler MVS (1976) Transmission without spikes between locust interneurons and motoneurones. Nature 262:222-224.

Burrows M, Siegler MVS (1978) Graded synaptic transmission between local interneurones and motoneurones in the metathoracic ganglion of the locust. J Physiol (Lond) 285:231-255.

Burrows M, Siegler MVS (1982) Spiking local interneurons mediate local reflexes. Science 217:650-652.

Burrows M, Laurent G, Field LH (1988) Nonspiking local interneurons receive direct inputs from a propriaceptor and contribute to local reflexes of a locust hindleg. J Neurosci 8:3085-3093.

Burrows M, Watson AHD, Brunn DE (1989) Physiological and ultrastructural characterization of a synaptic connection between identified motor neurons in the locust. Eur J Neurosci 1:111-126.

Byerly L, Leung HT (1988) Ionic currents of Drosophila neurons in embryonic cultures. J Neurosci 8:4379-4393.

Christensen TA, Hildebrand JG (1987) Male-specific, sex pheromoneselective projection neurons in the antennal lobes of the moth, Manduca sexta. J Comp Physiol 160A:553-569.

Connor JA, Stevens CF (1971) Voltage-clamp study of a transient outward membrane current in gastropod neural somata. J Physiol (Lond) 213:21-30.

DiCaprio RA (1989) Nonspiking interneurons in the ventilatory central pattern generator of the shore crab, Carcinus maenas. J Comp Neurol 285:83-106.

Finkell AS, Redman S (1984) Theory and operation of a single microelectrode voltage clamp. J Neurosci Methods 11:101-127.

Florio SK, Westbrook CD, Vasko MR, Bauer RJ, Kenyon JL (1990) Transient potassium currents in avian sensory neurons. J Neurophysiol 63:725-737.

Hagiwara S, Kusano K, Saito N (1961) Membrane changes of Onchidi$u m$ nerve cell in potassium-rich media. J Physiol (Lond) 155:470 489.

Hardie RC (1989) Ionic channels in dissociated retinal neurons of the blowfly. J Physiol (Lond) 418:203P.

Hardie RC, Weckström M (1990) Three classes of potassium channels in large monopolar cells in the blowfly Calliphora vicina. J Comp Physiol 167A:723-736.

Hardie RC, Voss D, Pons O, Laughlin SB (1991) Novel potassium channels encoded by the Shaker locus in Drosophila photoreceptors. Neuron, in press.

Hausen K (1982) .Motion sensitive interneurons in the optomotor system of the fly. I: the horizontal cells: structure and signals. Biol Cybern 45:143-156.

Hermann A, Gorman ALF (1981) Effects of 4-aminopyridine on potassium currents in a molluscan neuron. J Gen Physiol 108:37-77.

Hodgkin AL, Huxley AF (1952) Currents carried by sodium and potassium ions through the membrane of the giant axon of Loligo. J Physiol (Lond) 116:449-472.

Hoshi T, Aldrich RW (1988) Voltage-dependent $\mathrm{K}^{+}$currents and underlying single $\mathrm{K}^{+}$channels in pheochromocytoma cells. J Gen Physiol 91:73-106.

Iverson LE, Tanouye MA, Lester HA, Davidson N, Rudy B (1988) A-type potassium channels expressed from Shaker locus cDNA. Proc Natl Acad Sci USA 85:5723-5727.

Johnston D, Brown TH (1983) Interpretation of voltage-clamp measurements in hippocampal neurons. J Neurophysiol 50:464-485.

Kamb A, Iverson LE, Tanouye MA (1987) Molecular characterization of Shaker, a Drosophila gene that encodes a potassium channel. Cell $50: 405-413$.

Kamb A, Tseng-Crank J, Tanouye MA (1988) Multiple products of the Drosophila Shaker gene may contribute to potassium channel diversity. Neuron 1:421-430.

Kaneko A, Tashibana M (1985) A voltage-clamp analysis of membrane currents in solitary bipolar cells dissociated from Carassius auratus. J Physiol (Lond) 358:131-152.

Katz B (1949) Les constantes électriques de la membrane du muscle. Arch Sci Physiol 2:285-299. 
Kros CJ, Crawford AC (1990) Potassium currents in inner hair cells isolated from the guinea-pig cochlea. J Physiol (Lond) 421:263-291.

Laurent G (1987) The morphology of a population of thoracic intersegmental interneurons in the locust. J Comp Neurol 256:412-429.

Laurent G (1990) Voltage-dependent nonlinearities in the membrane of locust nonspiking local interneurons, and their significance for synaptic integration. J Neurosci 10:2268-2280.

Laurent G, Burrows M (1988) Direct excitation of nonspiking local interneurons by exteroceptors underlies tactile reflexes in the locust. J Comp Physiol 162A:563-572.

Laurent G, Burrows M (1989a) Distribution of intersegmental inputs to nonspiking local interneurons and motor neurons in the locust. $J$ Neurosci 9:3019-3029.

Laurent G, Burrows M (1989b) Intersegmental interneurons can control the gain of reflexes in adjacent segments of the locust by their action on nonspiking interneurons. J Neurosci 9:3030-3039.

Merickel M (1980) Design of a single electrode voltage clamp. J Neurosci Methods 2:87-96.

Mirolli M (1981) Fast inward and outward channels in a non-spiking neurone. Nature 292:251-253.

Mirolli M (1983) Inward and outward currents in isolated dendrites of Crustacea coxal receptors. Cell Mol Neurobiol 3:355-370.

Neher E (1971) Two fast components during voltage clamp on snail neurons. J Gen Physiol 58:36-53.

O'Dowd DK, Germeraad SE, Aldrich RW (1989) Alterations in the expression and gating of Drosophila sodium channels by mutations in the para gene. Neuron 2:1301-1311.

Papazian DM, Schwartz TL, Tenyel BL, Jan YN, Jan LY (1987) Cloning of genomic and complementary DNA from Shaker, a putative potassium channel gene from Drosophila. Science 237:749-753.

Pearson KG, Fourtner CR (1975) Nonspiking interneurons in the walking system of the cockroach. J Neurophysiol 38:33-52.

Pongs D, Kecskemethy N, Mueller R, Krah-Jentgens I, Baumann A, Kiltz H, Canal I, Llamazares S, Fercus A (1988) Shaker encodes a family of putative potassium channel proteins in the nervous system of Drosophila. EMBO J 7:1087-1096.

Rall W (1969) Time constants and electrotonic length of membrane cylinders and neurons. Biophys J 9:1483-1508.

Rall W (1977) Core conductor theory and cable properties of neurones. In: Handbook of physiology. The nervous system, Vol 1, Chap 3, pp 39-97. Bethesda, MD: American Physiological Society.

Rall W (1989) Cable theory for dendritic neurons. In: Methods in neuronal modelling (Koch C, Segev I, eds), pp 9-62. Cambridge, MA: MIT Press.

Ripley SH, Bush BMH, Roberts A (1968) Crab muscle receptor which responds without impulses. Nature 218:1170-1171.

Robertson RM, Pearson KG (1985) Neural networks controlling locomotion in locusts. In: Model neural networks and behavior (Selverston AI, ed), pp 21-35. New York: Plenum.

Rogawski MA (1985) The A-current: how ubiquitous a feature of excitable cells is it? Trends Neurosci 8:214-219.

Rudy B (1988) Diversity and ubiquity of potassium channels. Neuroscience $25: 729-749$.
Salkoff L (1983) Drosophila mutants reveal two components of fast outward current. Nature 302:249-251.

Schildberger K (1984) Multimodal interneurons in the cricket brain: properties of identified mushroom body cells. J Comp Physiol 154A: 71-79.

Schofield PK (1990) Oscillation of glial membrane potential in a localized region of the blood-brain barrier of an insect. J Exp Biol 148: 335-351.

Schwartz TL, Tempel BL, Papazian DM, Jan YN, Jan LY (1988) Multiple potassium-channel components are produced by alternative splicing at the Shaker locus in Drosophila. Nature 331:137-142.

Siegler MVS, Burrows M (1979) Morphology of local non-spiking interneurons in the metathoracic ganglion of the locust. J Comp Neurol 183:121-148.

Singh S, Wu CF (1989) Complete separation of four potassium currents in Drosophila. Neuron 2:1325-1329.

Solc CK, Aldrich RW (1988) Voltage-gated potassium channels in larval CNS neurons of Drosophila. J Neurosci 8:2556-2570.

Solc CK, Aldrich RW (1990) Gating of single non-Shaker A-type potassium channels in larval Drosophila neurons. J Gen Physiol 96: $135-165$

Solc CK, Zagotta WN, Aldrich RW (1987) Single-channel and genetic analyses reveal two distinct A-type potassium channels in Drosophila. Science 236:1094-1098.

Strausfeld NJ (1976) Atlas of an insect brain. New York: Springer.

Timpe LC, Schwarz TL, Tempel BL, Papazian DM, Jan YN, Jan LY (1988) Expression of functional potassium channels from Shaker cDNA in Xenopus oocytes. Nature 331:143-145.

Watkins BL, Burrows M, Siegler MVS (1985) The structure of locust nonspiking interneurons in relation to the anatomy of their segmental ganglion. J Comp Neurol 240:233-255.

Watson AHD, Burrows M (1985) The distribution of synapses on the two fields of neurites of spiking local interneurons in the locust. $J$ Comp Neurol 240:219-232.

Watson AHD, Burrows M (1988) Distribution and morphology of synapses on nonspiking local interneurons in the thoracic nervous system of the locust. J Comp Neurol 272:605-616.

Wei W, Covarrubias M, Butler A, Baker K, Pak M, Salkoff L (1990) $\mathrm{K}^{+}$current diversity is produced by an extended gene family conserved in Drosophila and mouse. Science 248:599-603.

Wilson WA, Goldner MM (1975) Voltage clamping with a single microelectrode. J Neurobiol 6:41 1-422.

Ypey DL, Clapham DE (1984) Development of a delayed outwardrectifying $\mathrm{K}^{+}$conductance in cultured mouse peritoneal macrophages. Proc Natl Acad Sci USA 81:3083-3087.

Zagotta WN, Aldrich RW (1990) Voltage-dependent gating of Shaker A-type potassium channels in Drosophila muscle. J Gen Physiol 95: 29-60.

Zagotta WN, Brainard MS, Aldrich RW (1988) Single-channel analysis of four distinct classes of potassium channels in Drosophila muscle. J Neurosci 8:4765-4779. 